\title{
ILE COPX
}

NBSIR 77-1271

DO NOT REMSOV

\section{Method of Testing, Rating and Estimating the Seasonal Performance of Central Air- Conditioners and Heat Pumps Operating in the Cooling Mode}

G E Kelly

W H. Parken, Jr

Mechanıcal Systems Program Center for Building Technology National Engineering Laboratory National Bureau of Standards Washıngton, D.C 20234

April 1978

Final Report

Sponsored by

The Department of Energy 12th and Pennsylvania Ave., NW Washington, D.C. 20461

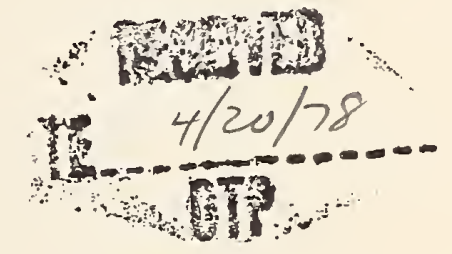



METHOD OF TESTING, RATING AND

ESTIMATING THE SEASONAL

PERFORMANCE OF CENTRAL AIR-

CONDITIONERS AND HEAT PUMPS

OPERATING IN THE COOLING MODE

G. E. Kelly

W. H. Parken, Jr.

Mechanical Systems Program

Center for Building Technology

National Engineering Laboratory

National Bureau of Standards

Washington, D.C. 20234

April 1978

Final Report

Sponsored by

The Department of Energy

12th and Pennsylvania Ave., NW

Washington, D.C. 20461



U.S. DEPARTMENT OF COMMERCE, Juanita M. Krop\$, Secretary

Dr. Sidney Harman. Under Secretary

Jordan J. Baruch, Assistant Secretary for Science and Technology

NATIONAL BUREAU OF STANDARDS. Ernest Ambler, Director 
Section

1. Scope and Purpose

1.1 Development of Recommended Test Procedures 2

1.1.1 Development of Recommended Test Procedures for Determining Cyclic Performance

1.1.2 Development of Test Procedures which Allow for Variations in Unit Design

1.2 Development of the Calculation Procedure for Estimating Seasonal Performance and Seasonal Cost of Operation

2. Recommended Testing and Rating Requirements 14

2.1 General

2.1.1 Requirements for Units with Single-Speed Compressors and Single-Speed Condenser Fans

2.1.2 Requirements for Units with Single-Speed Compressors and Multiple-Speed Condenser Fans

2.1.3 Requirements for Units with Two-Speed Compressors or Two-Compressors

2.1.4 Requirements for Units with Two-Speed Compressors or Two Compressors Capable of Varying the Sensible to Total Capacity (S/T) Ratio

2.1.5 Requirements for Split Systems

2.1.6 Additional Requirements

2.2 Recommended Test Procedures

2.2.1 Selection of Test Methods for Steady-State and Cyclic Operation

2.2.2 Test Room Requirements and Equipment Installation

2.2.3 Air Quantity Measurement

2.2.4 Test Operating Procedure and Results 


\section{Table of Contents (continued)}

Section

Page

2.2.5 Instrumentation and Data to be Recorded

2.2.6 Test Tolerances

2.2.7 Reduction of Data

3. Product Rating for the Seasonal Performance

3.1 Background

3.2.1 Recommended Procedure for Calculating an SEER for Units with Single-Speed Compressor and Single-Speed Condenser Fans

3.2.2 Recommended Procedure for Calculating an SEER for Units with Single-Speed Compressor and Multiple-Speed Condenser Fans

3.2.3 Recommended Procedure for Calculating an SEER for Units with Two-Speed Compressors or Two Compressors

3.2.4 Recommended Procedure for Calculating an SEER for Units with Two-Speed Compressors or Two Compressors Capable of Varying the Sensible to Total Capacity Ratio

3.2.5 Recommended Procedure for Calculating the Seasonal Cost of Operation in Different Climatic Regions of the Country

4. Limitations of the Recommended Test and Rating

Procedures and Future Work

4.1 Limitations of the Recommended Test and Rating Procedures

4.2 Additional Research Required 51

Nomenclature

Attachment A: Sample Calculations

Attachment B: General Considerations in Conducting the Cyclic Dry-Coil Tests. 
Figure 1 Schematic of the Various Modes of Operation for Units with Two-Speed Compressor or Two-Compressors.

Figure 2 Distribution of Cooling Load Hours Throughout the United States.

Table $1 \mathrm{a}$ and $1 \mathrm{~b}$

Summary of Test and Rating Requirements

Table 2 Test Operating and Test Condition Tolerances for Cyclic Dry-Coil Tests

Table 3 Distribution of Fractional Hours in Temperature Bins to be Used for Calculation of the SEER for Two-Speed Compressor and Two-Compressor Units. 



\section{Scope and Purpose}

The recommended test methods and the rating and calculation procedures proposed herein apply to air-cooled electrically-driven unitary air conditioners and heat pumps operating in the cooling mode as defined by the Air Conditioning and Refrigeration Institute (ARI) Standards 210-75 and 240-76. The purpose of the test and calculation procedures is to provide an estimate for the expected seasonal performance including the seasonal cost of operation for the above described units.

Currentiy, testing and rating requirements for unitary air conditioners are described in ARI Standard 210-75 and for heat pumps in ARI Standard 240-76. Test procedures used to evaluate this equipment are given in the American Society of Heating, Refriqerating and Air Conditioning Engineers (ASHRAE) Standard 37-69. For air-source units the current rating requirements are based on a steady-state test conducted at indoor dry-bulb and wet-bulb temperatures of $80^{\circ} \mathrm{F}\left(26.7^{\circ} \mathrm{C}\right)$ and $67^{\circ} \mathrm{F}\left(19.4^{\circ} \mathrm{C}\right)$, respectively, and an outdoor dry-bulb temperature of $95^{\circ} \mathrm{F}\left(35^{\circ} \mathrm{C}\right)$. In addition, for units which reject condensate to an outdoor condenser, an outdoor wet-buib temperature of $75^{\circ} \mathrm{F}\left(23.9^{\circ} \mathrm{C}\right)$ is specified.

In order to estimate the seasonal performance of an air conditioner or heat pump operating in the cooling mode, its capacity and input power must be known at outdoor temperatures other than $95^{\circ} \mathrm{F}\left(35^{\circ} \mathrm{C}\right)$. This 
information is required since air conditioners and heat pumps are utilized at such temperatures for many hours in various regions throughout the United States. Furthermore, experimental investigations have been conducted which indicate that the cycling "on" and "off" that these units undergo to satisfy comfort requirements also may have significant effect on the performance of the unit. The test procedure recommended in the following sections addresses the above factors; it does not however take into account the effect of consumer usage patterns on annual energy consumption since very little information is currently available on how consumers use central air conditioning equipment.

\subsection{Development of Recommended Test Procedures}

The recommended test methods are, for the most part, modifications of ASHRAE Standard 37-69. The steady-state tests are conducted and evaluated in a manner similar to that described in the ASHRAE Standard. In addition to the currently required test for rating at an outdoor dry-bulb temperature of $95^{\circ} \mathrm{F}\left(35^{\circ} \mathrm{C}\right)$, the recommended test method requires a steady-state test at an outdoor dry-bulb temperature of $82^{\circ} \mathrm{F}\left(27.8^{\circ} \mathrm{C}\right)$, which more closely typifies the average operating temperature for the country. A procedure has also been included to evaluate the cyclic performance of central cooling equipment.

* Facility Design and Construction Engineering Weather Data, AFM 88-8 Chapter 6, TM5-785, NAVFAC p-89., Depts. of the Air Force, the Army and the Navy, Washington, D.C. 1967. 
1.1.1 Development of Recommended Test Procedures for Determining Cyclic Performance

Indoor and outdoor ambient conditions are, for a large fraction of the time in regions throughout the country, such that an air conditioning unit must operate cyclically and with a wet evaporator coi1. It would therefore seem appropriate to test for the performance under these cyclic, wet coil conditions. Laboratory tests have been conducted to determine the performance under these conditions.

It was found that constant room ambient conditions are difficult to maintain and errors associated with the measurement of dry-bulb and wet-bulb temperatures can lead to large uncertainties in the cyclic sensible and latent capacities.

Results from laboratory tests, however, have indicated that cyclic wet-coil tests may be replaced by simpler and more accurate dry-coil tests. The dry-coil tests are conducted at a low indoor relative humidity, resulting in no generation of condensate. Specifically, the laboratory results indicate that when steady-state and cyclic dry-coil tests are conducted, the ratio of the cyclic energy efficiency ratio ( $E_{\text {cyc }}$, dry) to the steady-state energy efficiency ratio $\left(E E R_{\text {SS, dry }}\right)$ is essentially the same as the ratio of the EER's determined from cyclic and steady-state wet-coil tests at the same cooling load factor. The cooling load factor, CLF, is defined by the following expression: 


$$
\begin{aligned}
\text { CLF } & =\frac{Q_{c y c, d r y}}{\dot{Q}_{\text {ss,dry }} \times n \times \tau} \\
& =\frac{\dot{Q}_{\text {cyc,dry }}}{\dot{Q}_{\text {ss, dry }}} \cdot \frac{t_{\text {on }}}{\tau}
\end{aligned}
$$

The quantity $Q_{c y c}$ denotes the total cyclic cooling (sensible and latent) done by the unit over $n$ complete cycles of equal periods $\tau$, each consisting of a compressor on-time, $t_{o n}$, and compressor off-time. The quantity $\dot{Q}_{s s}$, dry denotes the steady-state total cooling capacity of the unit evaluated at the same ambient conditions as used in the cyclic test, while $\dot{Q}_{c y c}$,dry represents the average cyclic cooling capacity during an on-period and is equal to $Q_{c y c, d r y} / n t_{\text {on }}$.

A degradation coefficient, $C_{D}$, defined by the following expression, is determined from dry-coil tests:

$$
C_{D}=\frac{1-\frac{E_{\text {cyc }, d r y}}{E E R_{\text {SS,dry }}}}{1-C L F}
$$

Laboratory tests have indicated that $C_{D}$ is constant for cooling load factors ranging from approximately 0.1 to 1.0 and is also independent of ambient conditions. 
The energy efficiency ratio for cyclic wet-coil operation, $\left(E_{\text {cyc }}\right)$ at any cooling load factor can therefore be determined from the steady-state wet coil energy efficiency ratio and the value of the degradation factor by the following expression:

$$
E_{\text {CYC }}=E E R_{S S} P L F(C L F)
$$

where the part-load factor, PLF is defined as follows:

$$
\operatorname{PLF}(C L F)=\left[1-C_{D}(1-C L F)\right] \quad 1.4
$$

In succeeding sections, test methods are given to evaluate the cyclic performance and degradation coefficient, $C_{D}$. The cyclic dry-coil tests and steady-state dry-coil tests are referred to throughout the proposed test procedures as tests $D$ and $C$, respectively. While NBS does not believe tests $C$ and $D$ to be any more difficult to perform than the current test procedure required for ARI certification, they each require a minimum testing period of one and one half hours. It was therefore felt that allowing manufacturers to choose between performing tests $C$ and $D$ or accepting an assigned degradation coefficient, $C_{D}$. equal to 0.25 would not, at this time, have a significant effect on the labeling of residential central cooling equipment, and would go a long way toward making the new recommended testing and rating procedures acceptable to the unitary air conditioner industry. 


\subsubsection{Development of Test Procedures which Allow for Variations in Unit Design}

Currently, there is a variety of central air conditioning systems, many having unique modes of operation which affect their performance characteristics. The recommended test procedures have been developed and classified according to several design features in order to incorporate those features which may substantially change the unit's performance. The unit design features for which test procedures have been developed are given in Sections 2.1.1 through 2.1.5. Future additions and modifications of the recommended test procedures may be required in order to accurately reflect the performance of innovative central air conditioning equipment.

It is recognized that while test procedures should accurately reflect a particular unit's performance they may also be unduly burdensome to perform. The relative improvement in performance of a unit must therefore be weighed against complicated test procedures which accurately reflect such improvement. For example, in order to limit extensive testing, manufacturers of units designed to provide an adjustable latent cooling capacity by employing, as an installed item, controls which alter the effective evaporator coil size, may operate those controls in such a manner which results in the most effective evaporator coil size to be employed in the tests. The mode of operation for these units undergoing tests, must however, result in a system which would normally be encountered in residential use. Another example of the attempt to limit extensive testing while maintaining a reasonably accurate estimate 
of the seasonal energy efficiency ratio, is found in the recommended test procedure for units with single-speed compressor and multi-speed condenser fans. Rather than conducting tests at all condenser fan speeds, the recommended procedures require testing at a single condenser fan speed.

The recommended test procedures described herein should be reviewed in the future and judged according to their efficiency. Research is needed (see Section 4) to evaluate relative improvements in performance of innovative equipment and to develop simpler less time-consuming test procedures which will accurately reflect the improvement in performance.

7 


\subsection{Development of the Calculation Procedure for Estimating Seasonal Performance and Seasonal cost of Operation}

The determination of seasonal performance and cost of operation for unitary air conditioners and heat pumps operating in the cooling mode, included herein, is based upon a temperature bin method. This method, which is described in more detail below, establishes temperature bins at 5 degree $F$ increments, with the lower bound of the first bin established at $65^{\circ} \mathrm{F}\left(18.3^{\circ} \mathrm{C}\right)$. The number of hours in a cooling season in each temperature bin for different geographic locations may be determined from weather data*. For a particular climate of interest, the seasonal cooling requirement of a residence is determined for each temperature bin and the requirements are then summed over all temperature bins. The energy usage for each temperature bin is obtained by multiplying the number of hours of operation of the unit by the power input to the unit in that temperature bin. The seasonal energy usage may then be obtained by summing up the energy used in each temperature bin.

The capacity and power input to various central air conditioning units may not be a unique function of the outdoor temperature but is dependent additionaliy on the mode of operation of the unit. Various operating modes are utilized with units having two-speed compressors, two compressors, and having multi-speed condenser fans, etc. In the temperature bin method of analyses described in these recommended test procedures, allowance has been made for some of the effects

*For example: Facility Design and Construction Engineering Weather Data, AFM 88-8 Chapter 6, TM5-785, NAVFAC P-89., Depts. of the Air Force, the Army and the Navy, Washington, D.C. 1967. 
on performance due to modes of operation related to equipment characteristics. However, for purposes of discussion, the following analysis omits the effect of different operating modes and considers only an air conditioning system employing a single-speed compressor and a single-speed condenser fan.

The residential cooling requirements are determined by assuming: 1) a linear relationship between building cooling load, $B L\left(T_{j}\right)$, and outdoor dry-bulb temperature, $T_{j}(=5 j+62$, in degrees $F)$; 2) a zero load point of $\left.65^{\circ} \mathrm{F}\left(18.3^{\circ} \mathrm{C}\right) ; 3\right)$ a cooling unit oversizing factor of $10 \%$ at an outdoor temperature of $95^{\circ} \mathrm{F}\left(35^{\circ} \mathrm{C}\right)$. The dependence of building cooling load on the outdoor temperature is expressed by the following equation:

$$
B L\left(T_{j}\right)=\frac{5 j-3}{95-65} \cdot \frac{\dot{Q}_{S S}\left(95^{\circ} \mathrm{F}\right)}{1 . T}
$$

where $\mathrm{j}$ is the temperature bin number having integer values ranging from 1 to 8 .

The steady-state total cooling capacity of the central air conditioning unit at an outdoor temperature of $95^{\circ} \mathrm{F}\left(35^{\circ} \mathrm{C}\right)$ is denoted by $\dot{Q}_{S S}(95)$. The total seasonal cooling consumption, $Q$, is then obtained by multiplying the number of hours, $n_{j}$, in each temperature bin by the building cooling load at temperature $T_{j}$, and is expressed as follows:

$$
Q=N \sum_{j=1}^{8}\left[\frac{n_{j}}{N}\right] B L\left(T_{j}\right)
$$

where $n_{j}$ is the number of cooling season hours that occurred in temperature bin $\mathrm{j}$ and $\mathrm{N}$ is the total of all cooling season hours in the eight temperature bins. 
In order to determine the seasonal energy usage of central air conditioning units, several definitions are introduced. A load factor, $x\left(T_{j}\right)$ is first defined by the following expression:

$$
x\left(T_{j}\right)= \begin{cases}\frac{B L\left(T_{j}\right)}{\dot{Q}_{S S}\left(T_{j}\right)} & ; B L\left(T_{j}\right)<\dot{Q}_{S S}\left(T_{j}\right) \\ 1 & ; B L\left(T_{j}\right)>\dot{Q}_{S S}\left(T_{j}\right)\end{cases}
$$

At an outdoor temperature $T_{j}$, the central cooling unit is generally cycling "on" and "off", with a capacity $\dot{Q}_{c y c}\left(T_{j}\right)$, and having an on-time, $t_{\text {on }}$, and an off-time. The total period in one cycle is the sum of the on-time and off-time and is denoted by $\tau$. With proper sizing of the cooling unit capacity to the building load, the unit will meet most, if not all, the cooling requirements throughout the cooling season. Such conditions may be expressed mathematically as follows:

$$
B L\left(T_{j}\right)=\dot{Q}_{c y c}\left(T_{j}\right) \frac{t_{\text {on }}}{\tau}
$$

Utilizing equations $1.1,1.7$ and 1.8 , the following relationship between the cooling load factor, CLF, and the load factor $X\left(T_{j}\right)$ is obtained:

$$
C L F=X\left(T_{j}\right)
$$


The total energy used in temperature bin $j$ is the ratio of the total cooling done in temperature bin $j$ to the energy efficiency ratio. The total energy used in temperature bin $j$ is expressed as follows:

$$
E\left(T_{j}\right)=\frac{B L\left(T_{j}\right)}{\operatorname{EER}_{c y c}\left(T_{j}\right)} n_{j}
$$

Utilizing equation 1.7 , the above equation may be re-expressed in terms of the load factor as follows:

$$
E\left(T_{j}\right)=\frac{x\left(T_{j}\right) \dot{Q}_{S S}\left(T_{j}\right)}{E E R_{c y c}\left(T_{j}\right)} n_{j}
$$

Employing equations $1.3,1.9$ and the definition of energy efficiency ratio, equation 1.11 may be expressed as:

$$
\begin{aligned}
E\left(T_{j}\right) & =\frac{x\left(T_{j}\right) \dot{Q}_{S S}\left(T_{j}\right)}{\operatorname{PLF}\left(X\left(T_{j}\right)\right) E E R_{S S}\left(T_{j}\right)} n_{j} \\
& =\frac{X\left(T_{j}\right) \dot{E}_{S S}\left(T_{j}\right)}{\operatorname{PLF}\left(X\left(T_{j}\right)\right)} n_{j},
\end{aligned}
$$

where $\dot{E}_{S S}\left(T_{j}\right)$ denotes the steady-state power input to the unit at temperature $T_{j}$. 
The total electrical energy usage over the cooling season is then the sum of the energy usage in each temperature bin. This is expressed as follows:

$$
\begin{aligned}
E & =\sum_{j=1}^{8} E\left(T_{j}\right) \\
& =N \sum_{j=1}^{8} \frac{n_{j}}{N} \cdot \frac{X\left(T_{j}\right) \dot{E}_{S S}\left(T_{j}\right)}{\operatorname{PLF}\left(X\left(T_{j}\right)\right)}
\end{aligned}
$$

The seasonal energy efficiency ratio, SEER, is then expressed as follows:

$$
\overline{\text { SEER }}=\frac{Q}{E}
$$

When the above described method for the determination of seasonal performance is followed for single-speed compressor and single-speed condenser fan units for different climates throughout the U.S., the results in SEER do not vary by more than $10 \%$. Seasonal performance results using the temperature bin method have also been calculated by several manufacturers for two-speed compressor (with and without latent capacity control) and multi-speed condenser fan systems. The variations in seasonal performance of these units in different climates throughout the U.S. also appear to be less than 10\%. Moreover, it is likely that the variations in seasonal performance of identical units placed in similar residences with the same climate will show variations that are considerably larger than this (due to consumer usage patterns and variations in the performance of identical units). 
Since the variations in the seasonal performance of central cooling units due to individual usage patterns and model idiosyncrasies are estimated to be greater than the variations in performance due to climate, a normalized climate was generated. Generated temperature bin data is used in place of specific weather data (see Table 3, Section $3.2 .3)$. The fraction of the cooling season hours, $n_{j} / N$, in the various temperature bins used in the calculation of the seasonal performance corresponds to a distribution which is believed to approximate a national average and which results in an average operating outdoor temperature of $82^{\circ} \mathrm{F}\left(27.8^{\circ} \mathrm{C}\right)$. The average operating outdoor temperature was obtained by determining the average temperature in different regions of the nation (averaged with respect to the hours of compressor operation of a typical single-speed unit) and weighting these temperatures according to the number of central cooling units in each region. The seasonal energy efficiency ratios obtained with the above method agree within $10 \%$ of the results obtained with specific temperature bin data for different regions of the country when applied to units with single- and two-speed compressors with single- or multi-speed condenser fans.

For central ccoling units with single-speed compressors, a further simplification is possible in estimating the $\overline{\text { SEER }}$. The $\overline{\text { SEER }}$ is taken to be equal to the energy efficiency ratio of a cooling unit operating cyclically at a cooling load factor, CLF, equal to 0.5 and at an outdoor temperature of $82^{\circ} \mathrm{F}\left(27.8^{\circ} \mathrm{C}\right)$. This estimate of the SEER yields essentially the same results as the temperature bin method, employing temperature bin hours as specified in Table 3 in Section 3.2.3. 


\section{Recommended Testing and Rating Requirements}

The test and rating requirements for unitary central air conditioners and heat pumps operating in the cooling mode have been classified according to several basic design features. These design features are described in Sections 2.1.1 through 2.1.5. This classification can be expanded or modified as knowledge of the performance of these units increases, and provides a means for obtaining credit for improved performance of innovative equipment.

\subsection{General}

The test requirements generally consist of two steady-state wet-coil tests, labeled "A" and "B", and the selection of one of two methods for determining the dynamic performance. Tests $A$ and $B$ are referred to as "wet-coil" tests since virtually all present-day central air conditioners and heat pumps operating in the cooling mode will remove a considerable amount of water vapor from the indoor air at test $A$ and test $B$ ambient conditions, resulting in a wet evaporator coil. The first method for determining the dynamic performance (method 1 ) is to conduct steady-state and cyclic dry-coil tests. The second method (method 2) is to use an assigned degradation factor which describes the dynamic (cyclic) performance. The cooling equipment is then rated according to results of test $A$ and calculation of the SEER. A summary of the test and rating requirements is presented in Tables $1 \mathrm{a}$ and $1 \mathrm{~b}$. 
Table la

Summary of Test and Rating Requirements ${ }^{*}$

\begin{tabular}{l|c|c|c|c|} 
& \\
\end{tabular}

*Split Systems - The portion of the unit containing the compressor and indoor or outdoor coil shall be rated with each coil which the manufacturer sells

together with the compressor portion of the unit as a matched pair.

The applicable test and rating requirements described in Section

2.1.1 through 2.1.4 shall be used. 
Table 1B

Summary of Test and Rating Requirements;

Indoor and Outdoor Entering Air Temperature and Mode of Operation

\begin{tabular}{l|c|c|c|c|}
$\begin{array}{c}\text { Indoor } \\
\text { Dry-Bulb } \\
\text { Temperature }\end{array}$ & $\begin{array}{c}\text { Indoor } \\
\text { Wet-Bulb } \\
\text { Temperature }\end{array}$ & $\begin{array}{l}\text { Outdoor } \\
\text { Dry-Bulb } \\
\text { Temperature }\end{array}$ & $\begin{array}{l}\text { Outdoor } \\
\text { Wet-Bulb } \\
\text { Temperature }\end{array}$ & $\begin{array}{c}\text { Mode of } \\
\text { Operation }\end{array}$ \\
\hline Test A $80^{\circ} \mathrm{F}\left(26.7^{\circ} \mathrm{C}\right)$ & $67^{\circ} \mathrm{F}\left(19.4^{\circ} \mathrm{C}\right)$ & $95^{\circ} \mathrm{F}\left(35^{\circ} \mathrm{C}\right)$ & $75^{\circ} \mathrm{F}\left(23.9^{\circ} \mathrm{C}\right)$ & steady-state \\
\hline Test B $80^{\circ} \mathrm{F}\left(26.7^{\circ} \mathrm{C}\right)$ & $67^{\circ} \mathrm{F}\left(19.4^{\circ} \mathrm{C}\right)$ & $82^{\circ} \mathrm{F}\left(27.8^{\circ} \mathrm{C}\right)$ & $65^{\circ} \mathrm{F}\left(18.3^{\circ} \mathrm{C}\right)$ & steady-state \\
\hline Test C $80^{\circ} \mathrm{F}\left(26.7^{\circ} \mathrm{C}\right)$ & $\begin{array}{c}\text { See Note } \\
(2)\end{array}$ & $82^{\circ} \mathrm{F}\left(27.8^{\circ} \mathrm{C}\right)$ & $\ldots$ & steady-state \\
\hline Test D $80^{\circ} \mathrm{F}\left(26.7^{\circ} \mathrm{C}\right)$ & $\begin{array}{c}\text { See Note } \\
(2)\end{array}$ & $82^{\circ} \mathrm{F}\left(27.8^{\circ} \mathrm{C}\right)$ & $\cdots$ & $\begin{array}{c}\text { cyclic } \\
6 \text { min.on-time } \\
\text { min.off-time }\end{array}$ \\
\hline
\end{tabular}

(1) Applies only to those units which reject condensate to the outdoor coil.

(2) Shall at no time exceed that value of the wet-bulb temperature which results in the production of condensate by the indoor coil at the dry-bulb temperatures existing for the air entering the indoor portion of the unit. 


\subsubsection{Requirements for Units with Single-Speed Compressors and Single-Speed Condenser Fans}

Two steady-state wet-coil tests, referred to as test $A$ and test $B$, shall be performed according to the test procedures outlined in Section 2.2. Test $A$ and Test $B$ shall be performed with the air entering the indoor portion of the unit having a dry-bulb temperature of $80^{\circ} \mathrm{F}\left(26.7^{\circ} \mathrm{C}\right)$ and a wet-bulb temperature of $67^{\circ} \mathrm{F}\left(19.4^{\circ} \mathrm{C}\right)$. The dry-bulb temperature of the air entering the outdoor portion of the unit in Test $A$ sha 11 be $95^{\circ} \mathrm{F}\left(35^{\circ} \mathrm{C}\right)$; in Test $B$ it shall be $82^{\circ} \mathrm{F}\left(27.8^{\circ} \mathrm{C}\right)$.

The temperature of the air surrounding the outdoor portion of the unit in each test shall be the same as the outdoor entering air temperature, except for units or portions thereof intended to be installed only indoors, in which case the dry-bulb temperature surrounding that indoor portion of the unit shal1 be $80^{\circ} \mathrm{F}\left(26.7^{\circ} \mathrm{C}\right)$. For those units which reject condensate to the condenser, located in the outdoor portion of the unit, the outdoor wet-bulb temperature surrounding the outdoor portion of the unit shal1 be $75^{\circ} \mathrm{F}\left(23.9^{\circ} \mathrm{C}\right)$ in test $A$ and $65^{\circ} \mathrm{F}\left(18.3^{\circ} \mathrm{C}\right)$ in test $B$.

The cyclic performance shall be determined by either of the two following methods.

\section{Method 1}

Steady-state and cyclic dry-coil tests, referred to as test $\mathrm{C}$ and test $D$ respectively, shall be conducted according to the test procedures outlined in Section 2.2. The indoor dry-bulb temperature for tests $C$ and $D$ shall be $80^{\circ} \mathrm{F}\left(26.7^{\circ} \mathrm{C}\right)$. The indoor wet-bulb temperature 
for tests $C$ and $D$ shall be a value which does not result in formation of condensate on the indoor coil. It is recommended that an indoor wet-bulb temperature of $57^{\circ} \mathrm{F}\left(13.9^{\circ} \mathrm{C}\right)$ or less be used. The dry-bulb temperature of the air entering the outdoor portion of the unit shall be $82^{\circ} \mathrm{F}\left(27.8^{\circ} \mathrm{C}\right)$. The temperature of the air surrounding the outdoor portion of the unit shall be subject to the same conditions as the requirements for conducting test $B$.

Test $C$ shall be conducted with the unit operating steadily. Test D shall be conducted by manually cycling the unit "on" and "off". The unit shall cycle with the compressor "on" for 6 minutes and "off" for 24 minutes. The indoor fan shall also cycle "on" and "off", the duration of the indoor fan "on" and "off" periods being governed by the controls which the manufacturer normally supplies with the unit.

The results of tests $C$ and $D$ shall be used to calculate a degradation factor, $C_{D}$, by the procedures outlined in Section 2.2 .

\section{Method 2}

As an alternative to conducting tests $C$ and $D$, a value of $C_{D}=0.25$ is assigned to the degradation coefficient.

The capacity and power input of the unit determined from test $A$, the SEER and seasonal cost of operation shall be made available at the time of purchase to assist the consumer in selecting a unit which meets the design cooling requirements of his residence. The SEER and seasonal cost of operation shall be determined as described in Sections 
3.2.1 and 3.2.5 using the results of test $B$, the capacity measured in test $A$, and either method 1 or method 2 to evaluate the cyclic performance.

\subsubsection{Requirements for Units with Single-Speed Compressors and Multiple-Speed Condenser Fans}

The test requirements for multiple-speed condenser fan units shall be the same as the test requirements described in Section 2.1.1 for single-speed condenser fan units. Briefly, this requires that the two steady-state wet-coil tests $A$ and $B$ be conducted and either method 1 (conducting dry-coil tests $C$ and $D$ ) or method 2 (assigned degradation factor) be used to evaluate the cyclic performance. In addition, the condenser fan speed to be used in test $A$ shall be that speed which normally exists at an outdoor temperature of $95^{\circ} \mathrm{F}\left(35^{\circ} \mathrm{C}\right)$, and for tests $B, C$ and $D$ the fan speed shall be that which normally exists at an outdoor temperature of $82^{\circ} \mathrm{F}\left(27.8^{\circ} \mathrm{C}\right)$.

The values of capacity and power input of the unit determined from test $A$, the SEER and seasonal cost of operation shall be made available at the time of purchase to assist the consumer in selecting a unit which meets the design cooling requirements of his residence. The SEER and seasonal cost of operation shall be determined as described in Section 3.2.2 and 3.2.5 using the results of test $B$, the capacity measured in test $A$, and method 1 or method 2 to evaluate the cyclic performance. 


\subsubsection{Requirements for Units with Two-Speed Compressors or Two Compressors}

Test requirements are the same as described in Section 2.1.1 for single-speed compressor and condenser fan units, except that test $A$ and test $B$ shall be performed at each compressor speed. The condenser fan speed used in conducting test $A$ at each compressor speed shall be that which normaliy occurs at an outdoor dry-bulb temperature of $95^{\circ} \mathrm{F}\left(35^{\circ} \mathrm{C}\right)$. For test $\mathrm{B}$, the condenser fan speed at each compressor speed shall be that which normally occurs at an outdoor dry-bulb temperature of $82^{\circ} \mathrm{F}\left(27.8^{\circ} \mathrm{C}\right)$.

The cyclic performance of the unit shall be determined by either of the two following methods which are similar to the methods described in the requirements for single-speed units.

\section{Method 1}

Tests $C$ and $D$ shall be conducted at the low compressor speed with the same condenser fan speed as occurs in performance of test $B$. For those two-speed units in which the normal mode of operation involves the cycling "on" and "off" of the compressor at high speed, tests $C$ and $D$ must also be performed with the compressor operating at high speed and at a condenser fan speed that is normally encountered at test $A$ ambient conditions. 


\section{Method 2}

If tests $C$ and $D$ are not elected to be performed, then the following degradation factors shall be assigned:

$$
\begin{aligned}
& C_{D}^{k=1}=0.25 \text { low compressor speed }(k=1) \\
& C_{D}^{k=2}=0.25 \text { high compressor speed }(k=2)
\end{aligned}
$$

Units consisting of 2 compressors are subject to the same requirements as those units containing 2-speed compressors. "High speed" for 2-compressor units shall mean operation with both compressors, whereas "low speed" sha11 mean operation with the one compressor which normally operates at an outdoor temperature of $82^{\circ} \mathrm{F}\left(27.8^{\circ} \mathrm{C}\right)$.

The values of capacity and power input of the unit as determined from test $A$ at high compressor speed shall be made available at the time of purchase to assist the consumer in selecting a unit which meets the design cooling requirements of his residence. The SEER and seasonal cost of operation, determined from the results of tests $A$ and $B$ and either of the two methods for determining the degradation factor, shall be calculated according to the procedures outlined in Section 3.2.3 and 3.2.5. The SEER and seasonal cost of performance shall also be made available at the time of purchase. 
2.1.4 Requirements for Units with Two-Speed Compressors or Two Compressors Capable of Varying the Sensible to Total Capacity (S/T) Ratio

Some units employing a two-speed compressor or 2 compressors may also provide a method of varying the ratio of the sensible cooling capacity to the total cooling capacity $(S / T)$. For such units the test and rating requirements are the same as for two-speed compressor units, described in Section 2.1.3. The mode of operation selected for controlling the $S / T$ ratio in the performance of tests $A$ and $B$ at each compressor speed shall be at the discretion of the manufacturer, subject to the condition that it does not result in an operating configuration which is atypical of a normal residential installation. If method 1 is elected to be performed, tests $C$ and $D$ shall be conducted at low compressor speed (single compressor operating) with the same $S / T$ control mode as used in test $B$ performed with the low compressor speed (single compressor operating). Likewise, if the normal mode of operation involves cycling at high speed (two-compressor cycling). then tests $C$ and $D$ shall also be conducted at high compressor speed, (two compressor operating), and with the same $S / T$ control mode as in test $A$ performed with the high compressor speed (two compressor operating).

\subsubsection{Requirements for Split Systems}

The applicable test and rating requirements described in Sections 2.1.1 through 2.1.4 shall be used for split systems as well as for single package units. The portion of the unit containing the compressor and indoor or outdoor coil shall be rated with each coil which the manufacturer selis together with the compressor portion of the unit as a matched pair. 
Split systems shall be rated with the length and size of enterconnecting tubing specified in ARI Standard 210-75.

\subsubsection{Additional Requirements}

The following additional requirements shall apply to central air conditioners and heat pumps operating in the cooling mode. These additional requirements are 1 isted in the Air Conditioning and Refrigeration Institute (ARI) Standard 210-75 under the titles and section numbers listed below.

5.1.1 Values of the Standard Capacity Ratings

5.1.2 Values of the Standard Input Ratings

5.1.3 Values of the Standard Energy Efficiency Ratios

5.1.4.2 Voltage and Frequency

5.1.4.3 Cooling Coil Air Quantity. 


\subsection{Recommended Test Procedures}

For the most part, the following test procedures for central air conditioners and heat pumps operating in the cooling mode are modifications and additions to ASHRAE Standard 37-69. The following test procedures shall be utilized in conducting cyclic performance tests $C$ and $D$. Steady-state performance tests $A$ and $B$ shall be conducted as described in ASHRAE Standard 37-69 except where noted throughout this Section.

\subsubsection{Selection of Test Methods for Steady-State and Cyclic Operation}

Sections 3, 4, and 5 of ASHRAE Standard 37-69 describe the following four test methods that may be employed to evaluate the performance of unitary air conditioners and unitary heat pumps operating in the cooling mode:
a. Air-Enthalpy Method, Indoor Side
b. Air-Enthalpy Method, Outdoor Side
c. Compressor Calibration Method
d. Volatile Refrigerant Flow Method.

All steady-state wet- and dry-coil performance tests on single package units shall simultaneously employ the Air-Enthalpy Method on the Indoor Side and one other method consisting of either the Air-Enthalpy Method on the Outdoor Side or the Compressor Calibration Method. All steady-state wet- and dry-coil performance tests on split systems shall simultaneously employ the Air-Enthalpy Method on the Indoor Side and 
one other method selected from those listed above. All cyclic dry-coil performance tests shall employ only the Air-Enthalpy Method, Indoor Side.

\subsubsection{Test Room Requirements and Equipment Installation}

The test room requirements and equipment installation procedures are the same as those specified in Sections 11.1 and 11.2 of ASHRAE Standard 37-69. All tests shall be performed at the nameplate rated voltage and frequency. For central air conditioning equipment with dual nameplate voltage ratings, the tests shall be performed at both voltages or at the lower of the two voltages if only a single rating is to be published.

\subsubsection{Air Quantity and Measurement}

Units shall be installed and tested in such a manner that when operated under steady-state conditions the cooling coil and condenser airflows meet the requirements of Sections $5.1 .4 .3,5.1 .4 .4$, and 5.1.4.6 of ARI Standard 210-75.

\subsubsection{Test Operating Procedures and Results}

All steady-state wet-coil performance tests (tests $A$ and $B$ ) shall be conducted in accordance with the procedures described for cooling tests in Section 11.3 of ASHRAE Standard 37-69. The results from the wet-coil tests shall be analyzed in accordance with the coolingrelated requirements of Section 12 of ASHRAE Standard 37-69. 
For the steady-state wet-coil tests and the steady-state and cyclic dry-coil tests, those units which do not have indoor-air circulating fans furnished as part of the model shall have their sensible and total cyclic and steady-state capacities calculated as described in Section 2.2.7.

For each of the steady-state and cyclic dry-coil tests (tests C and $D$ ) the following test operating procedures and test results shall apply:

1. The test room reconditioning apparatus and the equipment under test shall be operated until equilibrium conditions are attained, but for not less than one hour before data for the steady-state test $C$ are recorded.

2. Test C (steady-state) shall then be performed with data recorded at ten minute intervals until four consecutive sets of readings are attained within the tolerances prescribed in Section 11.6 of ASHRAE Standard 37-69.

3. When the outdoor air-enthalpy method is used for test $C$ the above two requirements apply to both the preliminary test and the regular equipment test (see ASHRAE Standard 37-69, Section 3.6). When the compressor calibration method is employed, the above two requirements apply to both the equipment test and the compressor calibration test (see ASHRAE Standard 37-69, Section 4). 
4. For test $C$, the steady-state dry-coil capacity test results using the Indoor-Air Enthalpy Method shall agree within $6.0 \%$ with the results from one other simultaneously-conducted test method. The results of only the Indoor-Air Enthalpy Method shall then be used.

5. The cyclic dry-coil test $D$ shall be conducted immediately after the completion of the steady-state dry-coil test subject to item 4 listed above. The indoor average dry-bulb temperature for the steady-state and cyclic dry-coil tests shall be within $1.0^{\circ} \mathrm{F}\left(0.56^{\circ} \mathrm{C}\right)$ of each other. Likewise the outdoor average dry-bulb temperature for the steady-state and cyclic dry-coil tests shall be within $1.0^{\circ} \mathrm{F}\left(0.56^{\circ} \mathrm{C}\right)$ of each other.

6. Immediately after the steady-state dry-coil test is completed, the test unit shall be manually cycled "off" and "on" (using the "off" and "on" time periods specified in Section 2.1.1) until steadily repeating ambient conditions are again achieved in both the indoor and outdoor test chambers, but for not less than 2 complete "off"/"on" cycles. Without a break in the cycling pattern, the unit shall be run through an additional "off"/"on" cycle during which the required test data shall be recorded. During this last cycle, which is referred to as the test cycle, the indoor and outdoor test room ambient conditions shall remain within the tolerances specified in Section 2.2.6. 
7. During the cyclic dry-coil tests the condenser fan shall cycle "on" and "off" when the compressor cycles "on" and "off". The indoor air moving equipment shall also cycle "on" when the compressor cycles "on" and shall cycle "off" as governed by any automatic controls normally installed with the unit. This last requirement applied to units having an indoor fan time-delay. Units not supplied with an indoor-fan time delay shall have the indoor-air moving equipment cycle "on" and "off" as the compressor cycles "on" and "off".

8. The test installation shall be designed such that there will be no airflow through the cooling coil due to natural or forced convection while the indoor fan is "off".

9. For both the steady-state and cyclic dry-coil tests, the test results shall include the following quantities, calculated by the procedures outlined in Section 2.2.7:

a) Total cooling capacity, Btu/h

b) Indoor-side air flowrate, cfm of standard air

c) External resistance to indoor airflow, inches of water

d) Total energy input to equipment or energy input to all equipment components over the test cycle, watt-h.

e) Power input to the indoor fan for those units having an indoor fan as part of the model.

f) Degradation coefficient, $C_{D}$, to the nearest .02 .

10. Sections 12.1.5, 12.1.6, 12.1.7 of ASHRAE Standard 37-69 shall apply for both tests $C$ and $D$. 


\subsubsection{Instrumentation and Data to be Recorded}

The steady-state and cyclic performance tests shall have the same requirements pertaining to instrumentation and data as those specified in Section 10 and Table II of ASHRAE Standard 37-69. The following additional requirements shall apply only to the cyclic dry-coil performance tests.

(1) The dry-bulb temperatures of the air entering and leaving the cooling coil or the difference between these two dry-bulb temperatures shal1 be continuously recorded with instrumentation having a total system accuracy and precision of $\pm .3^{\circ} \mathrm{F}\left( \pm .17^{\circ} \mathrm{C}\right)$.

(2) Instrumentation used to measure the dry-bulb temperatures entering and leaving the coil or the difference between these two temperatures shall have a response time of 2.5 seconds or less. Response time is defined as the time required for the instrumentation to attain $63 \%$ of the final steady-state temperature difference when subjected to a step change in temperature difference of $15^{\circ} \mathrm{F}\left(8.3^{\circ} \mathrm{C}\right)$ or more.

(3) The eiectric energy used by a test unit shall be measured with a watt-hour meter that is accurate to within $\pm 0.5 \%$.

Suggested instrumentation is described in Attachment B, ASHRAE Standard 37-69 and ASHRAE Standard 41. 


\subsubsection{Test Tolerances}

A11 steady-state wet- and dry-coil performance tests shall be performed within the applicable operating and test condition tolerances specified in Section 11.6 and Table III of ASHRAE Standard 37-69. Two exceptions to these requirements shall apply to the steady-state dry-coil tests; these are 1) that the wet-bulb temperature of the air surrounding and entering the indoor portion of the unit shall not, at the dry-bulb temperature existing in the indoor section, exceed that value of the wet-bulb temperature that results in the formation of condensate on the indoor coil 2) the tolerances on the wet-bulb temperature of the air discharging from the indoor and outdoor portions of the unit shall not be specified.

The test condition and test operating tolerances for conducting the cyclic dry-coil test $D$ are given in Table 2. Test condition tolerance is defined as the maximum permissible variation of the average of the test observation from the desired test condition. Test operating tolerance is defined as the greatest permissible difference between maximum and minimum instrument observation during a test. When expressed as a percentage, the maximum allowable variation is the specified percentage of the arithmetical average of the observations. Variation in test conditions greater than the tolerances prescribed in Table 2 shall invalidate the test. 
In order to meet the required air temperature tolerances specified in Table 2 for the cyclic dry-coil tests, it is suggested that an electric resistance heater having a heating capacity approximately equal to the cooling capacity of the unit be installed and that it be cycled "on" and "off" as the test unit cycles "on" and "off" in the indoor test room. A similar heater with a heating capacity approximately equal to the sum of the cooling capacity and compressor and condenser fan power input should be installed and cycled "off" and "on" as the test unit cycles "on" and "off", respectively. This results in the maintenance of a constant cooling and heating load in the indoor and outdoor test chambers. Additional suggestions for conducting the cyclic dry-coil tests may be found in Attachment B.

\subsubsection{Reduction of Data}

The steady-state performance test results for the test unit's capacity shall be calculated using the equations specified in Section 3.7 of ASHRAE Standard 37-69*.

For steady-state performance tests, units which do not have indoorair circulating fans furnished as part of the model shall have their measured total and sensible steady-state cooling capacities adjusted by subtracting from these measured values $1250 \mathrm{Btu} / \mathrm{h}$ per 1000 SCFM $(0.78$ watts per $\mathrm{dm}^{3} / \mathrm{s}$ ) of indoor air flow and adding to the total steady-state power input 365 watts per 1000 SCFM ( 0.78 watts per $\left.\mathrm{dm}^{3} / \mathrm{s}\right)$ of indoor air

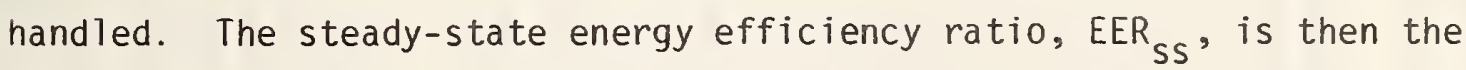
ratio of this adjusted total capacity, in $B t u / h$, to this adjusted total power input, in watts.

*The equation in Section 3.7 of ASHRAE Standard should read as follows: ${ }^{*} q_{t c i}=60 Q_{m i}\left(h_{a 1}-h_{a 2}\right) / v_{n}^{\prime}\left(1+w_{n}\right)$. 


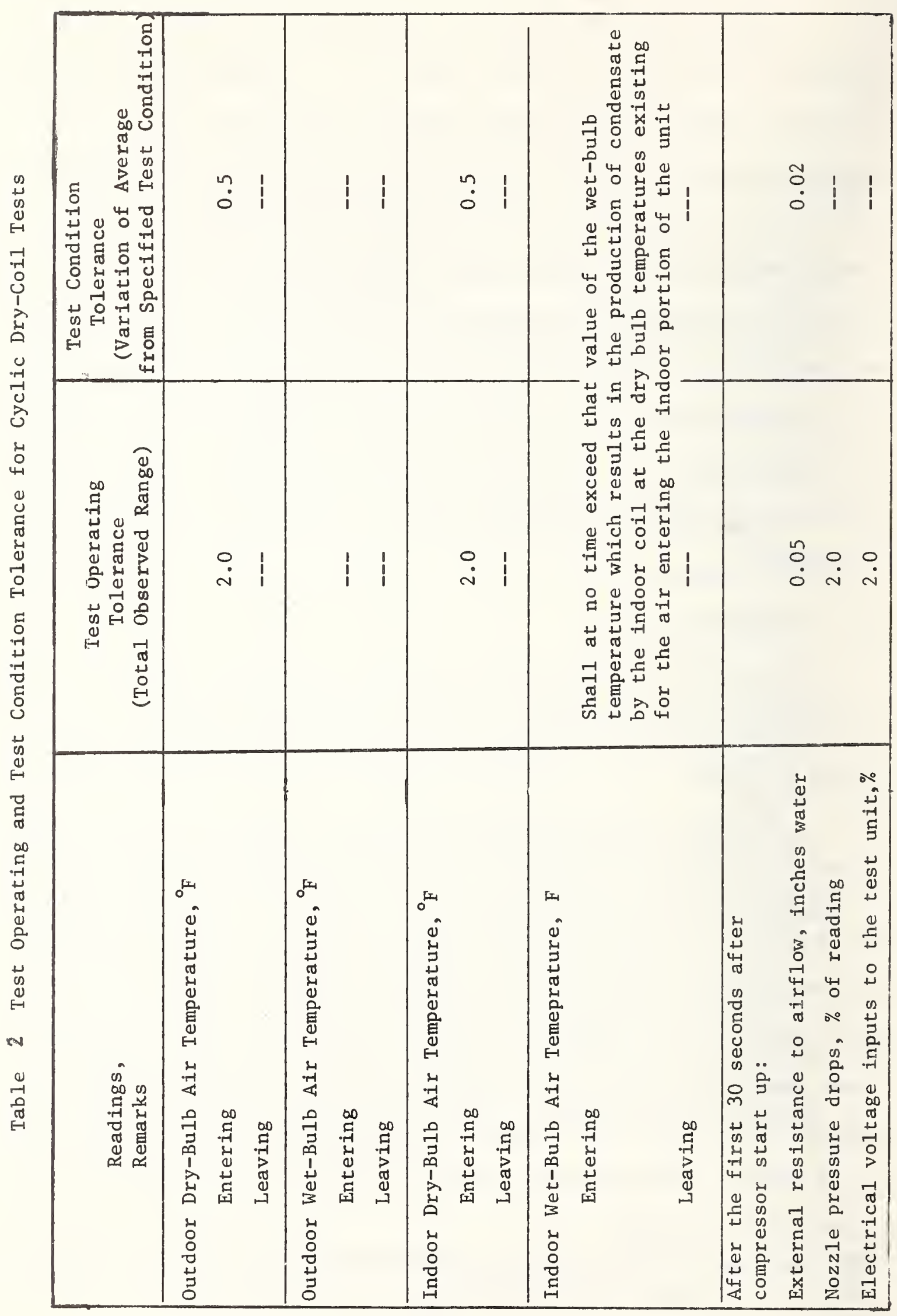


The results of the cyclic and steady-state dry-coil performance tests shall be used in the following equations to determine the cyclic capacity, $\dot{Q}_{c y c}$, dry , cyclic power input, $\dot{E}_{c y c, d r y}$, cyclic energy efficiency ratio, EER ${ }_{C y c}$, dry, and degradation factor, $C_{D}$. The various terms appearing in the following equations are defined in the Nomenclature.

$$
\begin{aligned}
& Q_{c y c, d r y}=\frac{60 \dot{\bar{V}} c_{p a} \Gamma}{\left[v_{n}^{\prime}\left(1+w_{n}\right)\right]} \\
& \dot{Q}_{c y c, d r y}=Q_{c y c, d r y} / t_{\text {on }} \\
& r=\int_{\text {(time indoor fan on) }}^{\text {(time indoor fan off) }}\left[T_{a 1}(t)-T_{a 2}(t)\right] d t \\
& C L F=\frac{Q_{c y c, d r y}}{\dot{Q}_{s S, d r y} \times \tau} \\
& E_{\text {cyc }, d r y}=\frac{Q_{c y c, d r y}}{E_{c y c, d r y}} \\
& E_{c y c, d r y}=\text { total electrical energy used during a test } \\
& \text { cycle consisting of } 1 \text { compressor "off" } \\
& \text { period and } 1 \text { compressor "on" period. }
\end{aligned}
$$




$$
\begin{aligned}
& C_{D}=\frac{1-\frac{E E R}{\text { Cyc,dry }}}{1-C L F} \text { ss,dry } \\
& \tau \quad-\text { Duration of time, in hours, for one } \\
& \text { complete cycle consisting of one } \\
& \text { compressor "on" time and one compressor } \\
& \text { "off" time. } \\
& t_{\text {on }} \text { Duration of time, in hours, of the } \\
& \text { compressor "on" time in one cycle } \\
& \text { of duration } \tau \text {. }
\end{aligned}
$$

For the cyclic performance tests, as in the steady-state performance tests, units which do not have indoor-air circulating fans furnished as part of the model shall have their total cooling done, $Q_{c y c}$, dry, and energy used, $E_{c y c}$,dry, in one complete cycle adjusted for the effect of circulating indoor-air equipment power. The value to be used for the circulating indoor air equipment power shall be $1250 \mathrm{Btu} / \mathrm{h}$ per 1000 SCFM (.78 watts per $\mathrm{dm}^{3} / \mathrm{s}$ ) of circulating indoor air. The energy usage required for indoor-air circulation during one cycle is the product of the circulating indoor air equipment power and the duration of time in one cycle that the circulating indoor air equipment is "on". The total cooling done shall then be the measured cooling done in one complete cycle minus the energy usage required in one complete cycle for indoor-air circulation. The total energy usage shall then be the sum of the energy usage required for indoor-air circulation in one complete cycle and the energy used by 
remaining equipment components in one complete cycle. The cyclic energy


cooling done in Btu, to the total energy usage, in watt-hours, where the total cooling done and total energy usage have been adjusted by the above-described procedures. 
3. Product Rating for the Seasonal Performance

\subsection{Background}

Sections 3.2.1 through 3.2.4 describe how an average seasonal energy


cooling equipment for which testing and rating requirements and procedures have been prescribed herein. After the SEER has been determined it is used in Section 3.2.5 to estimate the seasonal cost of operating such equipment in different climatic regions of the country.

Two different methods are employed to calculate seasonal energy efficiency ratios. In the first method, which is used for units with single speed compressors with single or multiple-speed condenser fans, it is assumed that the SEER is equal to the energy efficiency ratio of the cooling unit operating under cyclic conditions at an outdoor temperature of $82^{\circ} \mathrm{F}\left(27.8^{\circ} \mathrm{C}\right)$. A temperature of $82^{\circ} \mathrm{F}\left(27.8^{\circ} \mathrm{C}\right)$ has been estimated to be the average operating outdoor temperature for the country during the period of the year requiring cooling. This value was obtained by finding the average temperature in different regions of the country (averaged with respect to the hours of operation of a typical single speed unit) and weighting these average temperatures according to the number of central residential cooling units in each region. The second method, employed for units having two-speed compressors or two compressors, utilizes the results of tests $A$ and $B$ to define the capacity and power input requirements of the unit as a function of outdoor temperature. 
A temperature bin method of analysis is then used to calculate a seasonal energy efficiency ratio. The distribution of the fraction of cooling hours in the various temperature bins used in the calculation corresponds to a distribution which is believed to approximate a national average and which results in an average operating outdoor temperature of $82^{\circ} \mathrm{F}$ $\left(27.8^{\circ} \mathrm{C}\right)$. Both methods yield results which are virtually identical when they are applied to single-speed units.

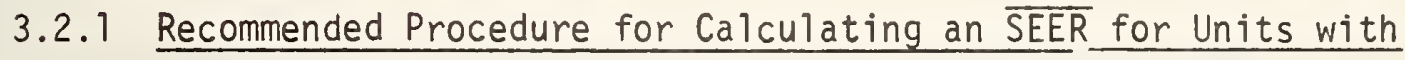 Single-Speed Compressor and Single-Speed Condenser Fans}

The seasonal energy efficiency ratio for units employing singlespeed compressors and single-speed condenser fans is based on the results of test $B$ and either of two methods outlined in Section 2.1.1 to account for the cyclic performance.

The seasonal energy efficiency ratio shall be determined by the following equation:

$$
\overline{\mathrm{SEER}}=[\operatorname{PLF}(0.5)]\left[\mathrm{EER}_{\mathrm{B}}\right]
$$

The part-load performance factor, $F L F(0.5)$, at a cooling load factor, CLF equal to 0.5 is determined from the following equation:

$$
\operatorname{PLF}(0.5)=1-C_{D}(1-0.5)
$$

The value of the degradation coefficient $C_{D}$ is obtained by either method 1 or method 2, as described in Section 2.1.2. 


\subsubsection{Recommended Procedure for Calculating an $\overline{\text { SEER }}$ for Units With Single-Speed Compressors and Multiple Speed Condenser Fans}

The seasonal energy efficiency ratio for units employing singlespeed compressors and multi-speed condenser fans is based on the energy efficiency ratio obtained for test $B$ and either of the two methods outlined in Section 2.1.2 to account for the performance under cyclic conditions. The energy efficiency ratio for test $B, E E R_{B}$, is obtained with the unit operating with a condenser fan speed normally encountered with test $B$-type ambient conditions. If tests $C$ and $D$ are conducted (i.e. method 1) to determine the cyclic degradation coefficient, $C_{D}$, then the tests are to be performed with the unit operating at the same condenser fan speed as encountered in test B.

The seasonal energy efficiency ratio shall be determined by the following equation:

$$
\overline{\operatorname{SEER}}=[\operatorname{PLF}(0.5)]\left[\mathrm{EER}_{\mathrm{B}}\right]
$$

The part load performance factor, PLF (0.5), at a cooling load factor, CLF, equal to 0.5 is determined by the following equation:

$$
\operatorname{PLF}(0.5)=1-C_{D}(1-0.5)
$$

The degradation coefficient, $C_{D}$, is evaluated by either conducting tests $C$ and $D$ (method 1 ) or using an assigned value of $C_{D}=0.25$ (method 2) as outlined in Section 2.1.2. 


\subsubsection{Recommended Procedure for Calculating an SEER for Units with Two-Speed Compressors or Two Compressors}

The calculation procedure described in this Section is based on the performance of tests $A$ and $B$ at each of the compressor speeds for two-speed compressor units, subject to the conditions on condenser fan speed described in Section 2.1.3. If elected to be performed, the cyclic performance tests $C$ and $D$ must be performed with the unit operating at the low compressor speed and with a condenser fan speed (for multi-speed fans) that is normally encountered at test $B$ ambient conditions. For those 2-speed units in which the compressor can cycle on and off at high speed, tests $C$ and $D$ must also be performed with the compressor cycling at high speed and at a condenser fan speed (for multi-speed fans) that is normally encountered at test $A$ ambient conditions.

Units operating with two compressors shall have the SEER calculated in the same manner as described below for two-speed compressor units. The superscripted index, $k=1$, (and the term "low speed") now designates that compressor which normally operates at an outdoor temperature of $82^{\circ} \mathrm{F}\left(27.8^{\circ} \mathrm{C}\right.$ ), and the superscript $\mathrm{k}=2$ (and the term "high speed") denotes operation with both compressors.

The results from each set of the A and B-type tests, for each compressor speed of the two-speed units shall be used in the following equation for the calculation of the $\overline{S E E R}$. 


$$
\overline{\text { SEER }}=\frac{\sum_{j=1}^{8} \frac{Q\left(T_{j}\right)}{N}}{\sum_{j=1}^{8} \frac{E\left(T_{j}\right)}{N}}
$$

The terms $\frac{Q\left(T_{j}\right)}{N}$ and $\frac{E\left(T_{j}\right)}{N}$, summed over temperature bins numbered one through eight, are evaluated at each temperature bin according to the four possible cases listed below. The four possible cases are also shown diagrammatically in Figure 1.

\section{Case I}

Units operating at low compressor speed, i.e. $k=1$, for which the steady-state cooling capacity, $\dot{Q}_{s s}^{k=1}\left(T_{j}\right)$, is greater than or equal to the building cooling load, $B L\left(T_{j}\right)$.

$$
\begin{aligned}
& B L\left(T_{j}\right) \leq Q_{S S}^{k=1}\left(T_{j}\right) \\
& x^{k=1}=\frac{B L\left(T_{j}\right)}{\dot{Q}_{S S}^{k=1}\left(T_{j}\right)} \\
& \frac{Q\left(T_{j}\right)}{N}=x^{k=1} \dot{Q}_{S S}^{k=1}\left(T_{j}\right) \frac{n_{j}}{N}
\end{aligned}
$$




$$
\begin{aligned}
& \frac{E\left(T_{j}\right)}{N}=\frac{x^{k=1} \dot{E}_{S S}^{k=1}\left(T_{j}\right)}{P L F^{k=1}} n_{j} \\
& N
\end{aligned}
$$

\section{Case II}

Units alternating between high $(k=2)$ and low $(k=1)$ compressor speeds to satisfy the building cooling load at temperature $T_{j}$

$$
\begin{gathered}
\dot{Q}^{k=1}\left(T_{j}\right)<B L\left(T_{j}\right) \leq \dot{Q}_{S S}\left(T_{j}\right) \\
x^{k=1}=\frac{\dot{Q}_{S S}\left(T_{j}\right)-B L\left(T_{j}\right)}{\dot{Q}_{S S}\left(T_{j}\right)-\dot{Q}_{S S}^{k=1}\left(T_{j}\right)} \\
x^{k=2}=1-x^{k=1} \\
\frac{Q\left(T_{j}\right)}{N}=\left[x^{k=1} \dot{Q}_{S S}^{k=1}\left(T_{j}\right)+x^{k=2} \dot{Q}_{S S}\left(T_{j}\right)\right]_{\frac{j}{N}}^{n_{j}} \\
\frac{E\left(T_{j}\right)}{N}=\left[x^{k=1} \dot{E}_{S S}\left(T_{j}\right)+x^{k=2} \dot{E}_{S S}^{k=2}\left(T_{j}\right)\right] \frac{n_{j}}{N}
\end{gathered}
$$




\section{Case III}

Units cycling on and off $(k=2)$ at high compressor speed in order to satisfy the building cooling load at temperature $T_{j}$.

$$
\begin{aligned}
& \dot{Q}^{k=1}\left(T_{j}\right)<B L\left(T_{j}\right) \leq \dot{Q}_{S S}^{k=2}\left(T_{j}\right) \\
& x^{k=2}=\frac{B L\left(T_{j}\right)}{\dot{Q}_{S S}^{k=2}\left(T_{j}\right)} \\
& \frac{Q\left(T_{j}\right)}{N}=x^{k=2} \dot{Q}_{S S}^{k=2}\left(T_{j}\right) \frac{n_{j}}{N} \\
& \frac{E\left(T_{j}\right)}{N}=\frac{x^{k=2} \dot{E}_{S S}^{k=2}\left(T_{j}\right)}{P L F^{k=2}} \frac{n_{j}}{N} \\
& P L F^{k=2}=1-C_{D}^{k=2}\left(1-x^{k=2}\right)
\end{aligned}
$$


Case IV

Units operating continuously at high compressor speed $(k=2)$ at outdoor temperature $T_{j}$.

$$
\begin{aligned}
& B L\left(T_{j}\right)>\dot{Q}_{S S}^{k=2}\left(T_{j}\right) \\
& \frac{Q\left(T_{j}\right)}{N}=\dot{Q}_{S S}^{k=2}\left(T_{j}\right) \frac{n_{j}}{N} \\
& \frac{E\left(T_{j}\right)}{N}=\dot{E}_{S S}^{K=2}\left(T_{j}\right) \frac{n_{j}}{N}
\end{aligned}
$$

The building cooling load, $B L\left(T_{j}\right)$ for the four cases described above for two-speed compressor, or two-compressor units, shall be obtained from the following equation:

$$
B L\left(T_{j}\right)=\frac{5 j-3}{95-65} \frac{\dot{Q}_{S S}^{k=2}(95 F)}{1.1}
$$

The fraction of hours, $\frac{n_{j}}{N}$, in each temperature bin, $j$, shall be obtained from Table 3.

In order to evaluate the steady-state capacity, $\dot{Q}_{S S}^{k}\left(T_{j}\right)$, and power input, $\dot{E}_{S S}^{k}\left(T_{j}\right)$, at temperature $T_{j}$ for each compressor speed, $k=1,2$, the results of tests $A$ and $B$ shall be used in the following equations:

$$
\begin{aligned}
& \dot{Q}_{S S}^{k}\left(T_{j}\right)=\dot{Q}_{S S}^{k}(95 F)+\frac{\dot{Q}_{S S}^{k}(82 F)-\dot{Q}_{S S}(95 F)}{95-82}(33-5 j) \\
& \dot{E}_{S S}^{k}\left(T_{j}\right)=\dot{E}_{S S}^{k}(95 F)+\frac{\dot{E}_{S S}(82 F)-\dot{E}_{S S}(95 F)}{95-82}(33-5 j)
\end{aligned}
$$




\section{Table 3}

Distribution of Fractional Hours in Temperature

Bins to be Used for Calculation of the SEER for

Two-Speed Compressor and Two-Compressor Units

Fraction of Total

Representative

Bin Number, Bin Temperature Temperature Bin

Range ( $\left.{ }^{\circ} \mathrm{F}\right)$

$\left({ }^{\circ} \mathrm{F}\right)$

1

2

3

4

5

6

7

8

$65-69$

67

72

77

82

87

92

97

102
Temperature Bin Hours

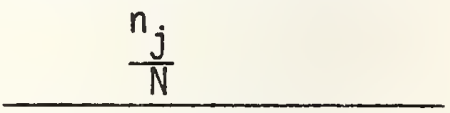

.214

.231

.216

.161

.104

.052

.018

.004 


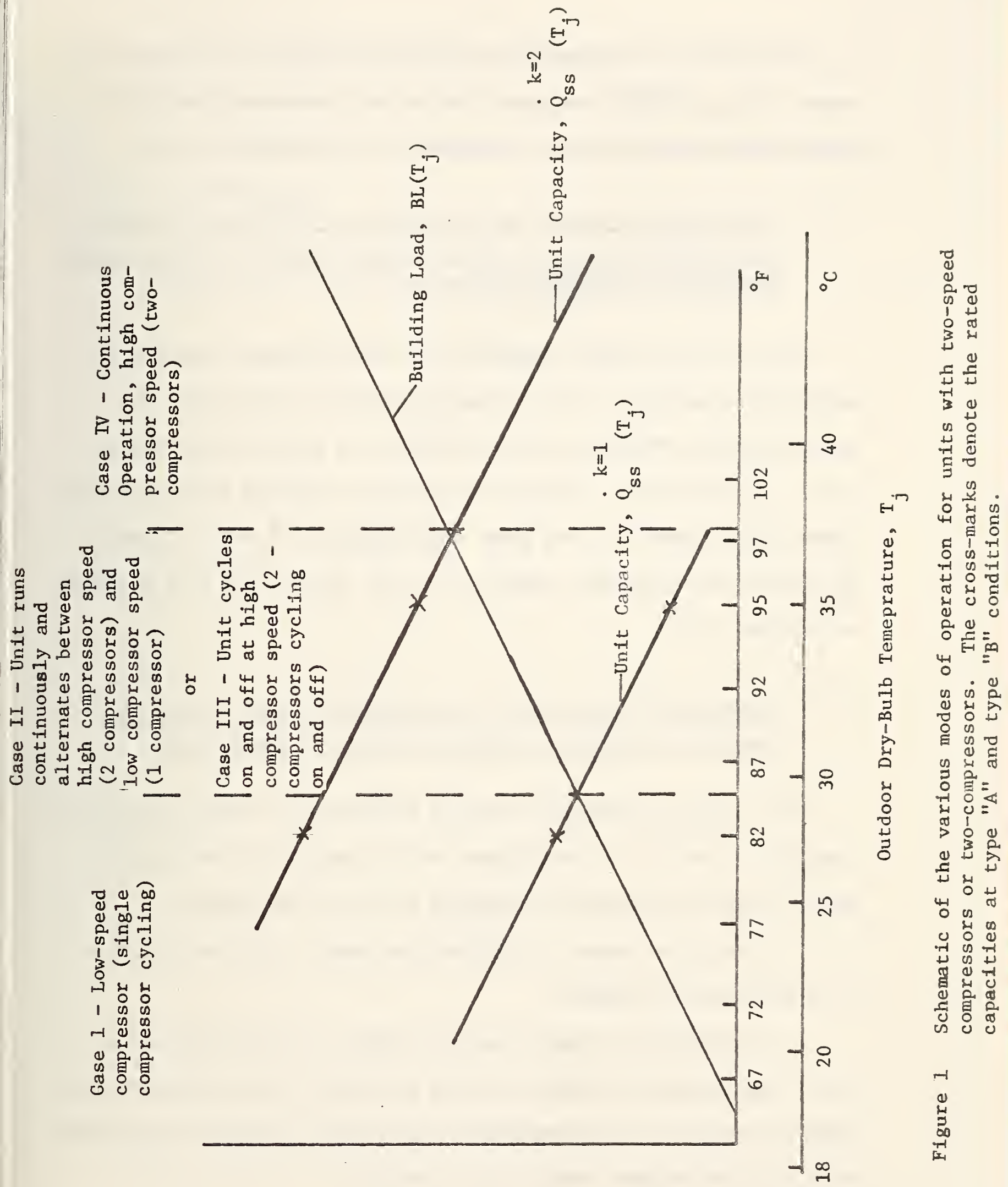


The value of the degradation coefficient, $C_{D}^{k=1}$ for low compressor speed cycling and $C_{D}^{k=2}$ for high speed on/off compressor cycling is determined by either method 1 or method 2, described in Section 2.1.3.

\subsubsection{Recommended Procedure for Calculating an SEER for Units with Two Speed Compressor or Two Compressors Capable of Varying the Sensible to Total Capacity Ratio}

Units with two-speed compressors or two compressors capable of varying the sensible to total capacity ratio $(S / T)$ shall have the seasonal energy efficiency ratio determined as described in Section 3.2.3. For such units, the mode of operation selected to determine the steady-state capacities, and power inputs $\dot{Q}_{S S}^{k}(95), \dot{Q}_{S S}^{k}(82), \dot{E}_{S S}^{k}(95)$, $\dot{E}_{S S}^{k}(82)$ at each compressor speed $k=1,2$, for tests $A$ and $B$ is outlined in Section 2.1.4.

3.2.5 Recommended Procedure for Calculating the Seasonal cost of Operation in Different Climatic Regions of the Country

The following procedures shall be followed to estimate the cost of operating a central air conditioner or heat pump during the cooling season in various geographic locations of the United States:

1. Obtain the number of cooling load hours, CLH, from Figure 2 for the region of interest.

2. Determine the rated capacity, CAP(95), in Btu per hour, at test A-type indoor and outdoor ambient conditions. For units with twospeed compressors or two compressors, the results from the A-type test which gave the highest capacity shall be used. 
3. By the procedures outlined in Sections 3.2.1 through 3.2.4, determine the seasonal energy efficiency ratio, $\overline{\text { SEER. }}$

4. The seasonal cost of operation shall be determined from the following equation:

Seasonal cost of Operation $=\mathrm{CLH} \times \frac{\mathrm{CAP}(95)}{\mathrm{SEER}} \times \frac{\text { cost per KWH }}{1000}$ 


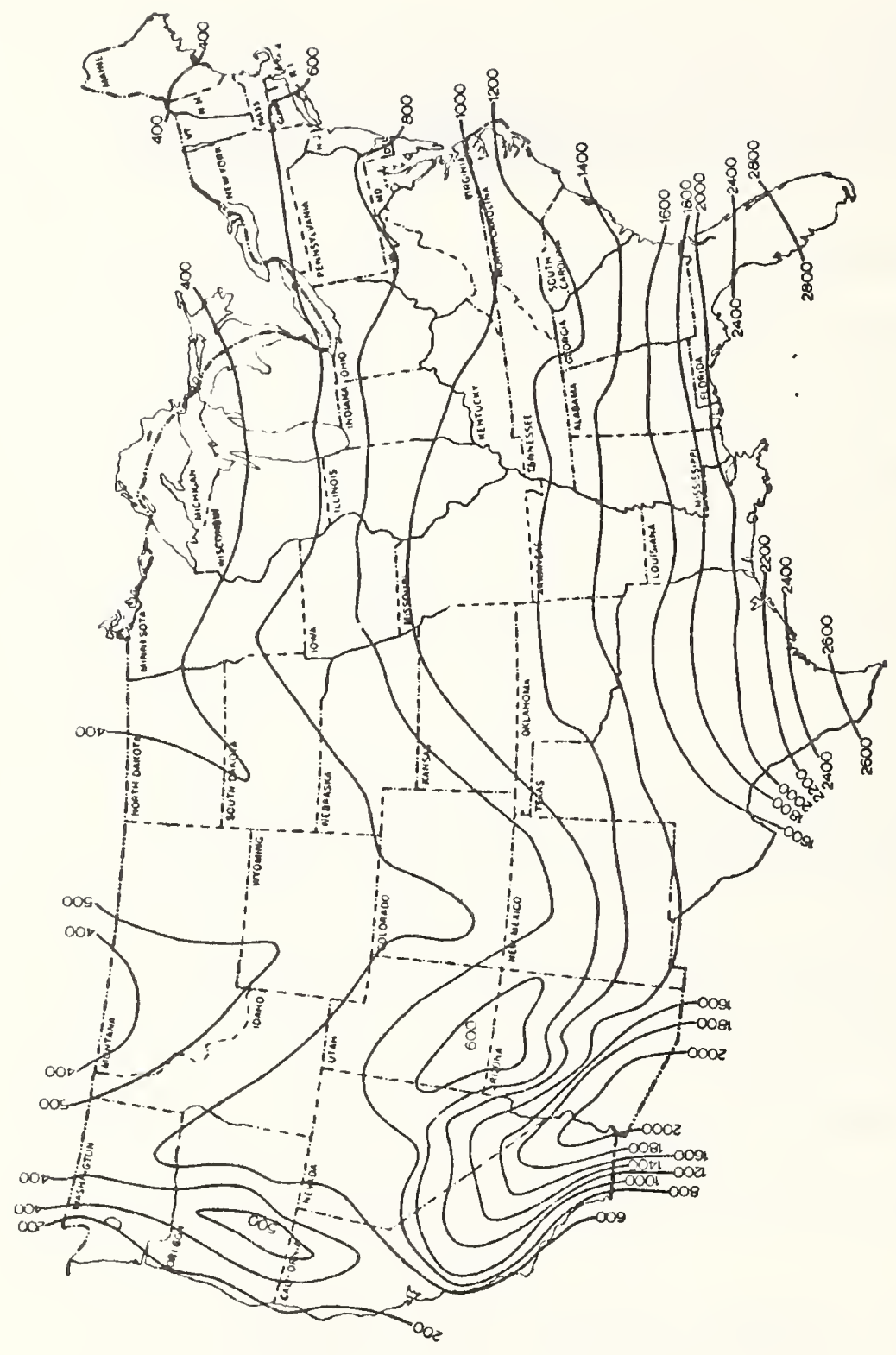

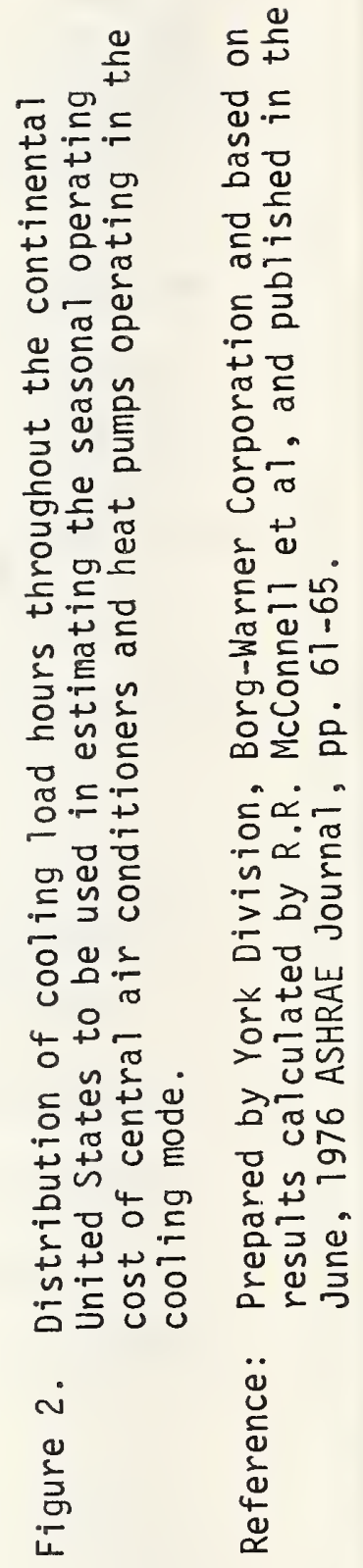


4. Limitations of the Recommended Test and Rating Procedures and Future Work

Several limitations are evident in the proposed test and rating procedures which indicate the need for future work. It is also evident from these limitations that test and rating procedures should not be considered as fixed, but should be continually updated and improved as our knowledge and understanding increases.

\subsection{Limitations of the Recommended Test and Rating Procedures}

In these proposed test and rating procedures, manufacturers of units capable of varying the sensible to total capacity $(S / T)$ ratio are allowed to evaluate the performance of such units at the most favorable $S / T$ ratio. Because of the resulting better performance, this may create an unfair advantage over other units whose $S / T$ ratio is fixed at such a value as to provide satisfactory comfort requirements for the consumer. This limitation of the test and rating procedures arises from the fact that the state-of-the-art knowledge of the cooling loads in residences is not advanced enough to allow NBS to specify with any degree of certainty, the latent cooling load that would be seen by an air conditioner or heat pump at various indoor and outdoor conditions in different types of homes and different climatic regions of the country.

In order to determine the cyclic performance of central airconditioning equipment, the proposed standard allows manufacturers the option of conducting tests $C$ and $D$ and calculating the degradation 
factor $C_{D}$, value equal to 0.25 . This allows units whose actual cyclic performance is worse than that indicated by the assigned degradation factor to be rated with a higher cyclic performance than actually exists.

The procedures specified in Section 3 assume that a central air conditioner or heat pump is used to meet the entire seasonal cooling requirement of a house continuously inhabited and maintained at a constant and reasonably comfortable indoor temperature. These assumptions will therefore result in a conservative estimate of the seasonal operating cost. Often, a consumer will use some sort of natural ventilation (opening windows, employing window fans, etc.) or a device to automatically adjust the daytime or nighttime thermostat setting, or simply to turn the air conditioning unit off when no one is at home in order to reduce his electricity bill. Under such circumstances, the recommended procedures would result in an overestimate of the seasonal cost of operating the central cooling equipment. On the other hand, if a consumer maintains a very low indoor temperature, his seasonal cost of operation could be appreciably greater than that calculated by the procedure outlined in Section 3.2.5. This limitation of the recommended rating procedures will be understood by the consumer if the label or brochure which is placed on the product clearly states that the seasonal cost of operation will vary with different usage patterns. 


\subsection{Additional Research Required}

The following additional research is needed to improve upon the recommended test and rating procedures and to remedy the limitations discussed in Section 4.1.

1. More laboratory work is needed to determine how to simplify and speed up the test procedures for evaluating steady-state and cyclic performance. For example, if an accurate and reliable method could be found for evaluating the cooling performance of central air conditioners and heat pumps under cyclic wet-coil conditions, tests $B, C$ and $D$ could be replaced by a single test for units with singlespeed compressors and single-speed condenser fans.

2. Research is needed to determine whether the degradation in performance due to cyclic operation can be accurately predicted from knowledge of a unit's design (e.g. capillary tube, expansion valve, compressor EER, etc.). If the degradation can be predicted, then it might be possible to eliminate all cyclic tests and assign a predicted degradation factor, $C_{D}$, to each type of unit.

3. Computer modeling and field studies are needed as quickly as possible to improve our knowledge of the cooling loads in residential buildings. Field studies are also needed to verify the accuracy of the recommended procedures for predicting annual operating costs and to quantify the effects of different consumer usage patterns on the annual energy consumption of central air conditioners and heat pumps operating in the cooling mode. 
4. Laboratory and field studies are needed to determine the best method of testing and rating innovative equipment. This is true even for two-speed compressor units, for which test and rating procedures have been specified. 
$B L\left(T_{j}\right) \quad$ Building cooling load at an outdoor dry-bulb temperature $T_{j}$, $[\mathrm{Btu} / \mathrm{h}]$

CAP(95) Highest rated capacity at test A-type ambient conditions, $[\mathrm{Btu} / \mathrm{h}]$

$C_{D} \quad$ Degradation factor for cyclic operation, defined by equation 1.2

CLF Cooling load factor, defined as the ratio of the total cyclic cooling done in a complete cycle of specified period consisting of an "on"-time and "off"-time to the steady-state cooling done over the same time period at constant ambient conditions. See equation 1.1 .

CLH Cooling load hours, defined as the number of hours in a cooling season that a building requires cooling. See figure 2.

$C_{\text {pa }} \quad$ Specific heat at constant pressure of air-water mixture per pound of dry air, $C_{p a}=0.24+0.444 W_{n}$, [Btu/lbF].

$\mathrm{dm}^{3} \quad$ Cubic decimeter

E Total seasonal energy usage, [watt-h]

$E\left(T_{j}\right) \quad$ Energy usage in temperature bin $j[$ watt- $h$ ], see equations 1.12 , and 3.9

$E_{\text {cyc }}$ Total electrical energy usage over a test cycle consisting of one compressor "off" period and one compressor "on" period. [watt-h]

$\dot{E}_{S S}\left(T_{j}\right)$ Steady-state total power input at an outdoor temperature $T_{j}$, [watts]. 
EER Energy efficiency ratio, defined as the ratio of total capacity of the unit to the total power input at specified indoor and outdoor ambient conditions, [Btu/watt-h]



EER $_{\text {cyc }}$ Cyclic energy efficiency ratio [Btu/watt-h]

j Outdoor dry-bulb temperature bin number, see Table 3

$\mathrm{N} \quad$ Total number of temperature bin hours

$\frac{n_{j}}{N} \quad$ Fractional number of temperature bin hours, see Table 3

PLF Part-load factor, defined as the ratio of the cyclic energyefficiency ratio to the steady-state efficiency ratio, see equation 1.4

Q Total seasonal cooling done, [Btu]

$Q_{\text {cyc }} \quad$ Total cooling done over a cycle consisting of one compressor "off" period and one compressor "on" period, [Btu]

$Q\left(T_{j}\right) \quad$ Total cooling done in temperature bin $j,[B t u]$, see equation 3.8

$\dot{Q}_{S S}\left(T_{j}\right)$ Total steady-state cooling capacity at an outdoor temperature $T_{j},[$ Btu/h] 
$\dot{Q}_{c y c}\left(T_{j}\right) \quad$ Cyclic total capacity at an outdoor temperature $T_{j},[B t u / h]$; defined as the ratio of the total cooling done over a given time period to the duration of time the compressor is on in that period

SEER Seasonal energy efficiency ratio, [Btu/watt-h]; defined as the ratio of the total cooling done to the total energy usage over a cooling season

$T_{j}$

Representative outdoor dry-bulb temperature for temperature bin $j,\left[{ }^{\circ} \mathrm{F}\right]$. See Table 3

$\mathrm{T}_{\mathrm{a} f}(\mathrm{t}) \quad$ Dry-bulb temperature of air entering the indoor coil, [ $\left.{ }^{\circ} \mathrm{F}\right]$

$\mathrm{T}_{\mathrm{a2}}(\mathrm{t}) \quad$ Dry-bulb temperature of air leaving the indoor coi1, $\left[{ }^{\circ} \mathrm{F}\right]$

t Time, $[\mathrm{h}]$

$t$ on Duration of time the compressor is on in one cycle consisting of a compressor on-time and a compressor off-time, [h]

Indoor air flowrate, [CFM] at the dry-bulb temperature, humidity ratio and pressure existing in the region of measurement

$v_{n}^{\prime} \quad$ Specific volume of air-water mixture, at the same dry-bulb temperature, humidity ratio, and pressure used in the determination of the indoor air flowrate, $\left[\mathrm{ft}^{3} / 1 \mathrm{~b}\right]$.

$w_{n} \quad$ Humidity ratio, $[1 b / 1 b]$

$x\left(T_{j}\right) \quad$ Load factor at an outdoor dry-bulb temperature $T_{j}$, defined by equation 1.7 
Time period consisting of a compressor on-time and compressor off-time [h]

$\Gamma \quad$ Defined by equation 2.3 , in $[F-h]$. 
Subscripts and Superscripts

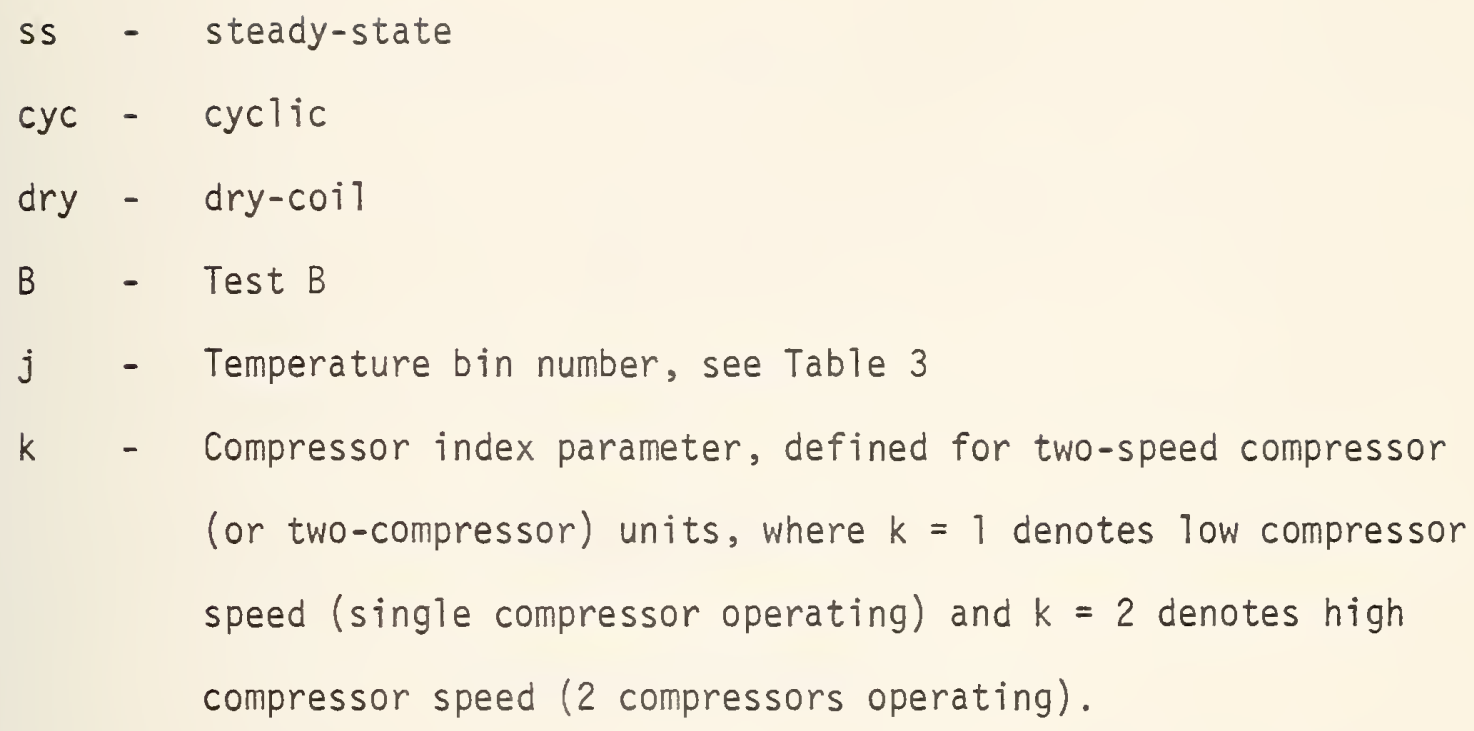

57 

Attachment A

Sample Calculations 
The following example is used to illustrate the calculation procedure for determining the SEER and seasonal cost of operation of a central air conditioning unit containing a two-speed compressor. Table Al contains the capacity and power input results at the low $(k=1)$ and high $(k=2)$ compressor speeds obtained from tests $A$ and $B$. The degradation coefficients, $C_{D}^{k=1}, C_{D}^{k=2}$, at low and high compressor speeds are also listed and are assumed to have been determined from tests $C$ and $D$.

Table A2 has been constructed to aid in the determination of the SEER. The data in the first three columns in Table A2 list the temperature bin data contained in Table 3. The data for each temperature bin in the remaining columns is determined from Table $A]$ and equations listed in Section 3.2.3 as described below.

1. (Column 4) Determine the building cooling load, $B L\left(T_{j}\right)$, from equation (3.24) for the representative outdoor temperatures, $T_{j}$, in each temperature bin.

$$
\begin{aligned}
& \text { For example, at } T_{j}=67^{\circ} \mathrm{F}, j=1: \\
& B L\left(67^{\circ} \mathrm{F}\right)=\frac{5 \times 1-3}{95-65} \frac{72000}{T . T}=4363.6 \mathrm{Btu} / \mathrm{h}
\end{aligned}
$$

2. (Columns 5, 6, 7, and 8) Using equations 3.25 and 3.26, determine the capacity, $\dot{Q}_{S S}^{k}\left(T_{j}\right)$, and total power input, $\dot{E}_{S S}^{k}\left(T_{j}\right)$, for each compressor speed and each temperature bin. 


$$
\begin{aligned}
& \text { For example, at } T_{j}=92^{\circ} \mathrm{F}, j=6: \\
& \dot{Q}_{S S}^{k=1}\left(92^{\circ} \mathrm{F}\right)=43000+\frac{51000-43000}{95-82}(33-5 \times 6)=44846 \mathrm{Btu} / \mathrm{h} . \\
& \dot{Q}_{S S}^{k=2}\left(92^{\circ} \mathrm{F}\right)=72000+\frac{80000-72000}{95-82}(33-5 \times 6)=73846 \mathrm{Btu} / \mathrm{h} . \\
& \dot{E}_{S S}^{k=1}\left(92^{\circ} \mathrm{F}\right)=5300+\frac{5100-5300}{95-82}(33-5 \times 6)=5253.9 \text { watts } \\
& \dot{E}_{S S}^{k=2}\left(92^{\circ} \mathrm{F}\right)=9300+\frac{8800-9300}{95-82}(33-5 \times 6)=9184.6 \text { watts. }
\end{aligned}
$$

3. (Column 9) Determine the applicable mode of operation of the airconditioning unit described in Section 3.2.3, cases 1 through 4 for the representative outdoor temperature in each temperature bin. For example, at a representative outdoor temperature of $67^{\circ} \mathrm{F}$ the capacity at the low compressor speed exceeds the building load and therefore case 1 is the applicable mode of operation.

As another example, at a representative outdoor temperature of $92^{\circ} \mathrm{F}$ the building cooling load is greater than the capacity at the low compressor speed and less than the capacity at the high compressor speed. Depending on the controls normally installed in the unit, the compressor may cycle between high and low speeds (case 2) or cycle "on" and "off" at high compressor speed (case 3 ) to satisfy the building cooling load. In this example, the air conditioning unit is assumed to operate in the mode described in case 2. 
4. (column 10 through 15) For each case and temperature bin listed in Table A2, determine where applicable the load factors, $X^{k}$, part load factors, $P L F^{k}$, and the terms $\frac{Q\left(T_{j}\right)}{N}, \frac{E\left(T_{j}\right)}{N}$.

The above-mentioned quantities are calculated using the equations listed in each of the four possible cases described in Section 3.2.3.

Example: $\quad T_{j}=67^{\circ} \mathrm{F}, j=1$, case 1

from equations $3.7,3.8,3.9,3.10$ :

$x^{k=1}=\frac{4363 \cdot 1}{6023 i}=.0725$

$\frac{Q\left(67^{\circ} \mathrm{F}\right)}{N}=.0725 \times 60231 \times .214=934.5 \mathrm{Btu} / \mathrm{h}$

$\mathrm{PLF}^{\mathrm{k}=1}=1-0.20(1-.0725)=.815$

$\frac{E\left(67^{\circ} \mathrm{F}\right)}{N}=\frac{.0725 \times 4869.2 \times .214}{.815}=92.69$ watts

Example: $\quad T_{j}=92^{\circ} \mathrm{F}, j=6$, case 2

from equations $3.12,3.13,3.14,3.15$ :

$x^{k=1}=\frac{73846 \cdot-58909}{73846 \cdot-44846}=.515$

$\frac{Q\left(92^{\circ} \mathrm{F}\right)}{N}=[.515 \times 44846+.485 \times 73846] \times .052=3063.4 \mathrm{Btu} / \mathrm{h}$

$\frac{E\left(92^{\circ} \mathrm{F}\right)}{N}=[.515 \times 5253.9+.485 \times 9184.6] \times .052=372.3$ watts 
5. The seasonal energy efficiency ratio may be determined by summing the individual terms $\frac{Q\left(T_{j}\right)}{N}, \frac{E\left(T_{j}\right)}{N}$ listed in the last two columns of Table A2, over the eight temperature bins.

From equation 3.5 :

$$
\overline{\text { SEER }}=\frac{25666}{2784}=9.22
$$

\section{Determination of the Seasonal cost of Operation}

In order to determine the seasonal cost of operation of the central air conditioner in the present example, the procedure outlined in Section 3.2.5 is followed. It is assumed that the central air conditioner is installed in the Washington, D.C. area and that the cost of electricity is $\$ 0.040$ per $\mathrm{KWH}$.

From Figure 1, the number of cooling load hours, CLH, for the Washington, D.C. area is approximately 850. The highest measured capacity obtained from test $A$, in this example unit is $72000 \mathrm{Btu} / \mathrm{h}$ and the $\overline{\text { SEER }}$ has been determined to be 9.2 .

The seasonal cost of operation is determined by equation 3.27 :

$$
\text { Seasonal Cost of Operation }=850 \times \frac{72000}{9.2} \times \frac{.040}{1000}=\$ 266 \text {. }
$$


Table Al. Sample Data Required to Calculate the $\overline{\text { SEER }}$ for a Central Air Conditioning Unit Containing a Two-Speed Compressor.

\begin{tabular}{|c|c|c|}
\hline & $\begin{array}{l}\text { Low } \\
\text { compressor } \\
\text { speed, } \\
k=1\end{array}$ & $\begin{array}{l}\text { High } \\
\text { compressor } \\
\text { speed, } \\
k=1\end{array}$ \\
\hline $\mathrm{Q}_{S S}(95 F), B t u / h$ & 43,000 & 72,000 \\
\hline$\dot{Q}_{S S}^{k}(82 F), B t u / h_{1}$ & 51,000 & 80,000 \\
\hline $\mathrm{E}_{s s}^{\mathrm{k}}(95 \mathrm{~F})$, watts & 5300 & 9300 \\
\hline$\dot{E}_{s s}^{k}(82 F)$, watts & 5100 & 8800 \\
\hline $\begin{array}{l}\text { *Degradation } \\
\text { Factor, } C_{D}^{k}\end{array}$ & 0.20 & 0.20 \\
\hline
\end{tabular}

* assumed to be obtained from tests $C$ and $D$. 


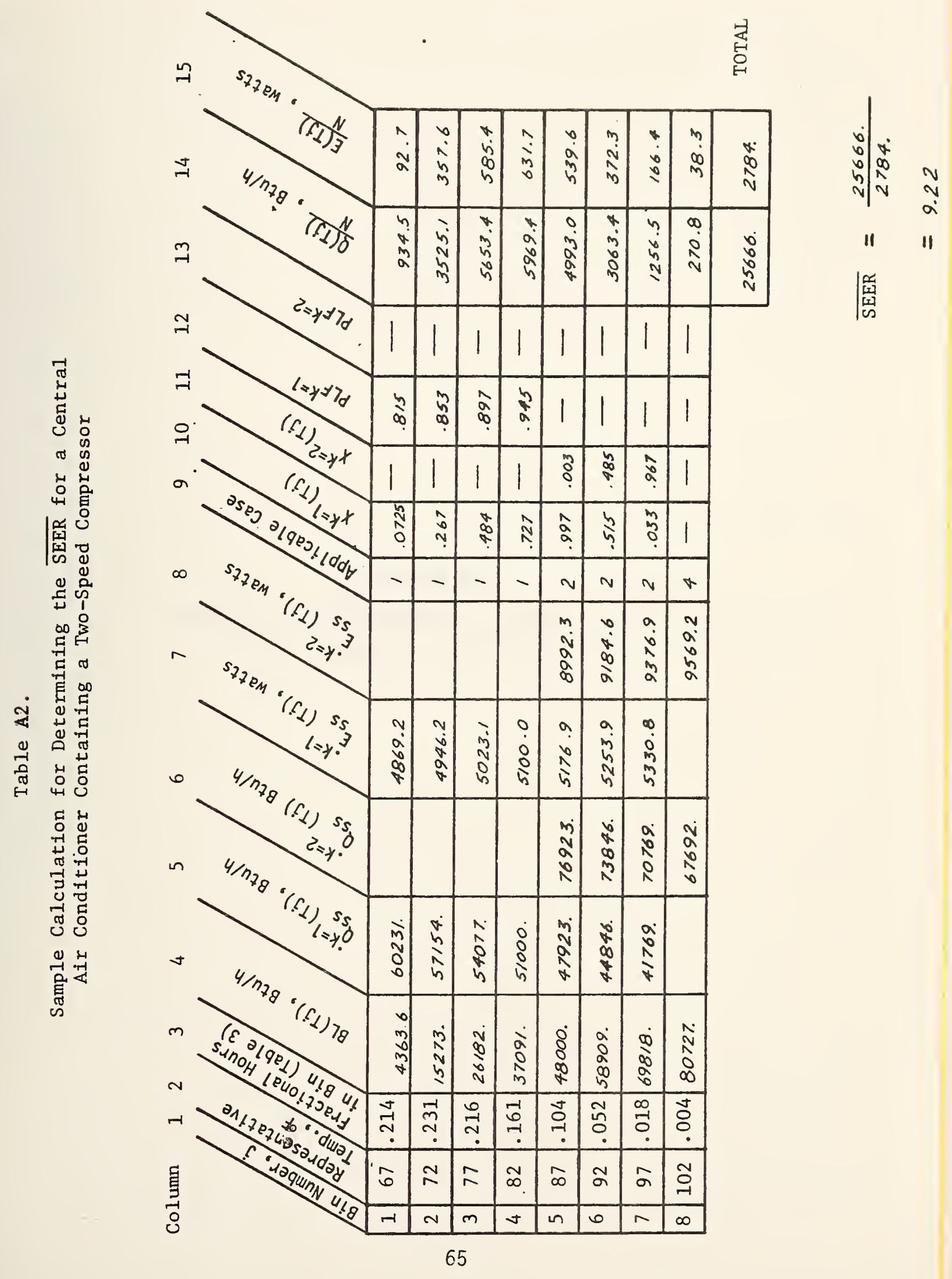



Attachment B

General Considerations in Conducting the Cyclic Dry-Coil Tests 
Suggested test facility design and instrumentation for determining the performance of central air conditioning equipment are described in ASHRAE Standard 37-69. ATthough intended for steady-state testing, the suggestions given in the Standard are readily applicable or adaptable to cyclic performance testing. The recommended test and rating procedures require that the cyclic capacity be determined by the Indoor-Air Enthalpy Method as stated in the above-mentioned Standard. Since there is no independent simultaneously conducted test method used to serve as a check on the determination of cyclic performance, precautions should be taken to assure an accurate determination. The following considerations are directed to alleviating a few potential probiems which may occur during the cyclic performance tests.

Control of Indoor-Side and Outdoor-Side Ambient Air Temperature

Supplementary air reconditioning equipment is generally required to absorb the cooling and heating output of the air-conditioning equipment to be tested and to control the surrounding and entering ambient air temperatures. During cyclic performance testing, a periodically fluctuating load is imposed on the air-reconditioning equipment, making ambient conditions more difficult to control than in steady-state testing. The air-reconditioning equipment should have sufficient capacity to absorb the load, as well as to handle the air flow imposed on it by the equipment under test. 
One method of reducing the periodically fluctuating loads due to cyclic operation is to install electric heaters in an appropriate location on the discharge sides of both the indoor and outdoor portions of the unit. The heating capacity of the indoor-side heater should approximately equal the cooling capacity of the unit. The heating capacity of the outdoor-side heater should approximately equal the sum of the cooling capacity and power input to the compressor and condenser fan.

ASHRAE Standard 37-69 requires a test room into which the outdoor portion of the central air conditioning equipment to be tested is installed and the entering air temperature is controlled. The air within the outdoor-side test room should be well circulated, especially when the test equipment is cycled "off", to prevent air temperature stratification; however, air velocities in the vicinity of the unit should be kept low. These remarks also apply to those installations utilizing an indoor test room. Precautions should be taken to prevent air discharging from the indoor and outdoor portions of the unit from bypassing the supplementary air reconditioning equipment and re-entering the respective portions of the unit.

\section{Air Temperature Measurement}

The important air temperatures to be measured in the determination of the cyclic performance are the air temperatures entering the indoor and outdoor portions of the test unit and the temperature difference of the air entering and leaving the indoor portion of the unit. These 
air temperature measurements should be made with suitable devices having a precision, accuracy and response time within the tolerances specified in the recommended test procedures.

A number of methods for measuring air temperatures, several of which are described below, are described in ASHRAE Standard 41. The air temperature entering portions of the unit can be measured by utilizing several thermocouples connected electrically in parallel and installed in an appropriate fashion across the air inlet portions of the unit or in the entering air ducts. In order to measure the temperature difference of the air entering and leaving the indoor portion of the unit, a thermopile, consisting of a number of thermocouples connected electrically in series, may be utilized. The thermopile is appropriately installed in the entering-air and discharge-air ducts attached to the indoor portion of the unit. The millivolt signal generated by the thermocouples attached to the air-entering portions of the unit may be directed to strip chart recorders. The signal generated by the thermopile may also be directed to a strip chart recorder and the determination of the capacity (see Section 2.2.6 equations 2.1 and 2.3) facilitated by measuring the area under the curve generated by the recorder.

Several potential errors may occur in the measurement of air temperature within ducts, especially during the cyclic testing of central air conditioning equipment. In order to measure the temperature difference across the indoor portion of the unit, or the temperature of the supply air, a uniform air velocity and temperature distribution 
must be assured. Sources causing possible nonuniformities in the supply air temperature are poor mixing of the supply air, heat transfer through the duct wal1, and thermal storage effects of the duct. The latter source of error is due to measuring the air temperature near the duct wall, where the duct wall and air near the wall may exhibit a different rate of temperature decrease than the mainstream supply air when the unit is turned "on". Another source of error in the supply air temperature measurement is the heat transfer through the thermocouple wire.

A suitable mixing device may have to be installed in the supply duct to reduce the nonuniformities in the air temperature and velocity distribution. The supply air duct should be heavily insulated and sealed from leaks and air temperatures within the duct measured reasonably close to the unit. If thermocouples are used, several inches of thermocouple wire beyond the junction should also be left in the supply air duct to reduce the error associated with the heat transfer through the wire.

\section{Air Flowrate Measurement}

ASHRAE Standard 37-69 describes in detail instrumentation and calculation procedures which may be used to determine the indoor-side air flow rate of the test unit. During the cyclic tests, static pressures and temperatures needed to determine the air flow rate may be varying and measurement of these data may be facilitated by taking these measurements towards the end of the "on" period. 


\section{Measurement of Electrical Energy Usage}

In order to determine the dry-coil cyclic and steady-state energy efficiency ratios, the energy input to the indoor air circulating fan, condenser fan, compressor, and control circuit must be determined. The energy usage can be measured by a number of commercially available watt-hour meters. These meters commonly utilize registers and/or pulse generators which generate pulses proportional to the energy usage and are of sufficient resolution and accuracy to be used in the cyclic performance tests.

\section{Additional Considerations}

During cyclic testing, provisions should be made to prevent either natural or forced convection through the indoor portion of the unit when the unit is cycled "off". The unit should be installed and operated in such a manner that the normal air circulating pattern around the outdoor portion of the unit is maintained. Installation of the unit should also be consistent with the manufacturer's recommendations. 
NBS-IIUA IREV. 7.73\}

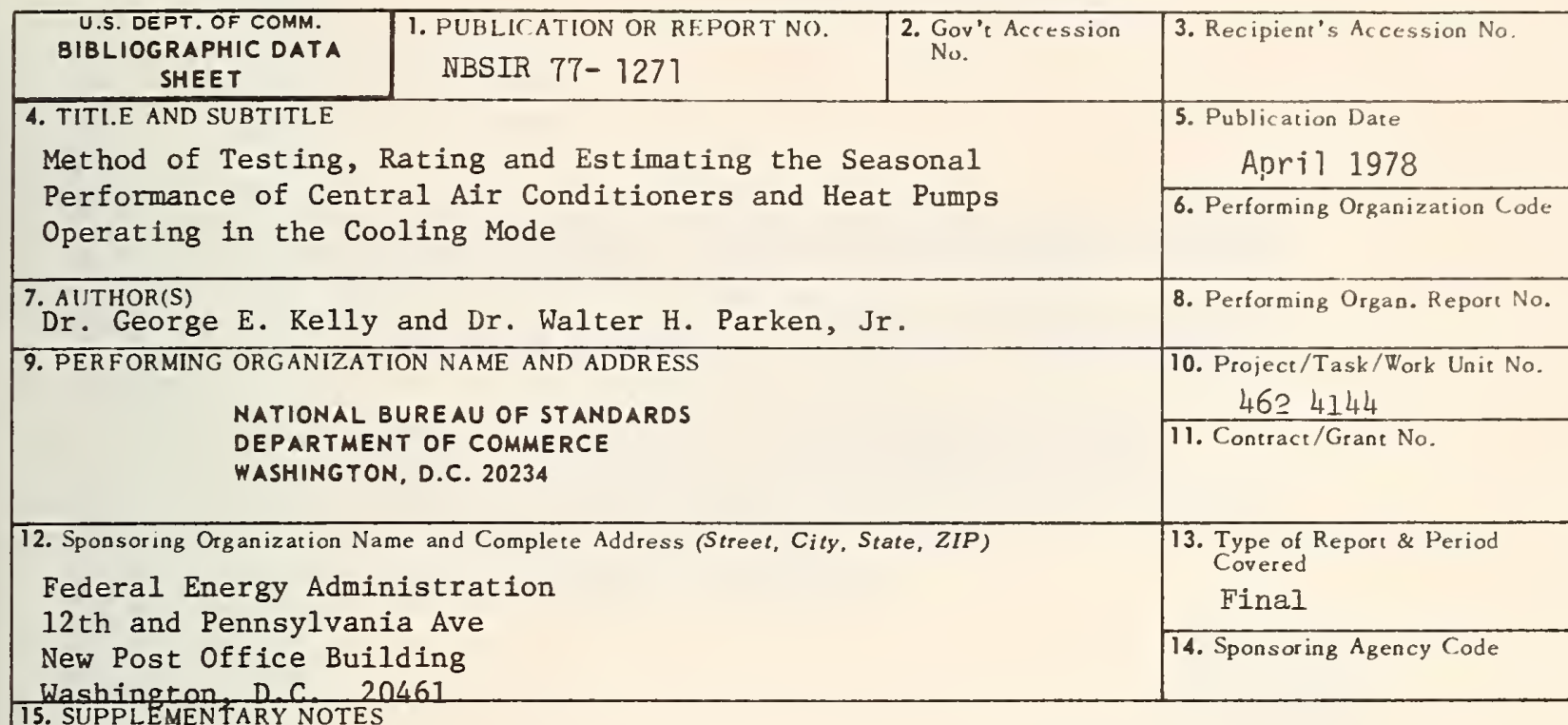

15. SUPPLEMENTARY NOTES

16. ABSTRACT (A 200-word or less factual summary of most significant information. If document includes a significant bibliography or literature survey, mention it here.)

The National Bureau of Standards has made a study of the part-load and seasonal performance of residential central air conditioners and heat pumps operating in the cooling mode. This document outlines methods for testing and rating these units which account for the variation in performance due to part-load operation and change in outdoor air temperature. A calculation procedure is presented which can be used to estimate the seasonal performance and seasonal cost of operation of residential central-cooling equipment.

17. KEY WORDS (six to twelve entries; alphabetical order; capitalize only the first letter of the first key word unless a proper name; separated by semicolons)

central air conditioners, heat pumps, rating procedure, seasonal cost of operation, test method
18. AVAILABILITY

$$
\mathrm{X} \text { Unlimited }
$$

[ Jor Official Distribution. Do Not Release to NTIS

[ ] Order From Sup. of Doc., U.S. Government Printing Office Washington, D.C. 20402, SD Car. No. C13

X Order From National Technical Information Service (NTIS) Springfield, Virginia 22151

\begin{tabular}{|l|c|}
\hline $\begin{array}{l}\text { 19. SECURITY CLASS } \\
\text { (THIS REPURT) }\end{array}$ & $\begin{array}{c}\text { 21. NO. OF PAGES } \\
\text { UNCI. ASSIFIED }\end{array}$ \\
\hline $\begin{array}{l}\text { 20. SECURITY CLASS } \\
\text { (THIS PAGE) }\end{array}$ & $\begin{array}{c}\text { 22. Price } \\
\$ 5.25\end{array}$ \\
\hline UNCLASSIFIED)
\end{tabular}


